\title{
Integument pattern formation involves genetic and epigenetic controls: feather arrays simulated by digital hormone models
}

\author{
TING-XIN JIANG ${ }^{1}$, RANDALL B. WIDELITZ1 ${ }^{1}$, WEI-MIN SHEN ${ }^{3}$, PETER WILL ${ }^{3}$, DA-YU WU², CHIH-MIN LIN ${ }^{1}$, \\ HAN-SUNG JUNG ${ }^{4}$ and CHENG-MING CHUONG ${ }^{*}, 1$ \\ ${ }^{1}$ Department of Pathology, ${ }^{2}$ Department of Cellular and Neurobiology, ${ }^{3}$ Computer Science Information Sciences Institute, \\ University of Southern California, Los Angeles, California, USA and ${ }^{4}$ Dept. of Oral Biology, Division in Histology, \\ College of Dentistry, Yonsei University, Seoul, Korea
}

\begin{abstract}
Pattern formation is a fundamental morphogenetic process. Models based on genetic and epigenetic control have been proposed but remain controversial. Here we use feather morphogenesis for further evaluation. Adhesion molecules and/or signaling molecules were first expressed homogenously in feather tracts (restrictive mode, appear earlier) or directly in bud or inter-bud regions (de novo mode, appear later). They either activate or inhibit bud formation, but paradoxically colocalize in the bud. Using feather bud reconstitution, we showed that completely dissociated cells can reform periodic patterns without reference to previous positional codes. The patterning process has the characteristics of being self-organizing, dynamic and plastic. The final pattern is an equilibrium state reached by competition, and the number and size of buds can be altered based on cell number and activator/inhibitor ratio, respectively. We developed a Digital Hormone Model which consists of (1) competent cells without identity that move randomly in a space, (2) extracellular signaling hormones which diffuse by a reaction-diffusion mechanism and activate or inhibit cell adhesion, and (3) cells which respond with topological stochastic actions manifested as changes in cell adhesion. Based on probability, the results are cell clusters arranged in dots or stripes. Thus genetic control provides combinational molecular information which defines the properties of the cells but not the final pattern. Epigenetic control governs interactions among cells and their environment based on physical-chemical rules (such as those described in the Digital Hormone Model). Complex integument patterning is the sum of these two components of control and that is why integument patterns are usually similar but non-identical. These principles may be shared by other pattern formation processes such as barb ridge formation, fingerprints, pigmentation patterning, etc. The Digital Hormone Model can also be applied to swarming robot navigation, reaching intelligent automata and representing a self-re-configurable type of control rather than a follow-the-instruction type of control.
\end{abstract}

KEYWORDS: periodic patterning, reaction - diffusion, tissue engineering, complexity, self-configuring robot

The formation of each organ goes through induction, morphogenesis, and differentiation stages. During the morphogenesis stage, the shape, pattern, and size that constitute the functional form of an organ are laid down. Pattern formation is one of the fundamental processes that take place during the morphogenesis stage. The easiest patterns to observe are found on the integument (Bereiter-Hahn et al., 1986). The striking examples of Integument pattern formations are the avian plumages, leopard dots, tiger stripes, etc. In Fig. 1, we can appreciate examples of different integument patterns which grace our eyes that are produced by Nature.
How do these patterns form? Are they under strict genetic control? Then, why are many patterns similar but not identical. Are they under epigenetic control? Then why do patterns appear to be amazingly consistent in animals of the same species? In the past, many theoretical models have been developed for pattern formation, but they lack molecular and cellular foundations (summarized in Held, 1992). During the past decade, major molecular signaling pathways underlying development have been identified. Many laboratories using different experimental models have attempted to unlock the mechanisms underlying pattern formation. Results obtained from the Drosophila integument suggest

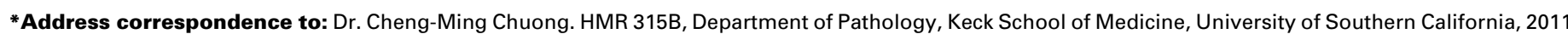
Zonal Avenue, Los Angeles, CA 90033, USA. Fax: +1-323-442-3049. e-mail: chuong@pathfinder.usc.edu 
that many patterns are under major genetic control (Simpson, 2002). However, are vertebrate integument patterns also under genetic control? Here we will first present a few general examples, then we will use the avian integument as the experimental model to study the mechanisms of pattern formation.

\section{Patterns on the integument}

\section{Skin appendages}

Hairs and feathers are regulated by morphogenesis factors which determine both the location and form of the follicles. Many of the theories pertaining to feather follicle formation have been applied toward hair follicle formation and patterning. Nagorcka and Mooney (1985) postulated that a reaction - diffusion mechanism could account for variations in hair distributions producing different patterns in different regions of an individual's skin, such as stripes and spots. These patterns are predicted to be interchanged by altering a single parameter. An example of regional specificity in patterning can be seen in the different feather types and pigmentation patterns present in different regions of the pheasant integument (Fig. 1A).

The development of hair, sweat glands and teeth can all be blocked by a pathway regulating anhidrotic ectodermal dysplasia (Headon et al., 2001). This pathway consists of Eda (Tabby in mice) and its receptor, Edar (downless in mice) (Pispa and Thesleff, 2003). Binding of Eda to Edar triggers epithelial appendage differentiation. While an understanding of the basic pathway is understood, details remain to be determined. These studies demonstrate a strong genetic component is involved in integument patterning.

Hairs, feathers, sweat glands, etc. are all epithelial derivatives of epithelial - mesenchymal interactions (Chuong edit, 1998). The development of hair follicles have been described (Paus et al., 1999). In the mouse, the primary follicle was laid down first. They are followed by the secondary hair follicles (Botchkarev et al., 2002) that are positioned in between. In some animals, the arrangements appear random (e.g., human), while in others the arrangements appear to be regular and follow some pattern (e.g., sheep) (Moore et al., 1998). Later rounds of initiation can produce compound hair follicles, where existing follicles become branched. Using sheep skin as a model, the follicle population density was found to inversely correlate with the follicle diameter. In general follicle size corresponded to dermal papilla size (Moore et al., 1998).

\section{Fingerprints and skin ridges}

It is said that no two people have the same fingerprints. Fingerprints develop early in fetal development and are complete by about 7 months after conception. They do not change after the configuration is set unless the finger sustains a wound. While similar genetic factors would tend towards identical patterns, local environmental factors within the amnion can influence the shape of fingerprints, so even identical twins have some identifiable variations that can be distinguished (Fig. 1C; Jain et al., 2002). Although all fingerprints contain similar elements (ridges which form arches, loops, whorls) they are arrayed differently in each individual. There can be variations in ridge thickness, inter-ridge distance, ridge depth, the number of ridges which comprise a given element, ridge anomalies, element placement and orientation.
How do these papillary ridges develop with such distinct morphologies? The fact that even identical monozygotic twins have some differences in their fingerprints indicates that fingerprints are distinct because they are formed following rules dictated by reaction - diffusion rather than through a pre-patterning mechanism. Hence, each individual develops fingerprints, but the arrangements come from competition between cellular properties and the local micro-environment.

What purpose do they serve? Papillary ridges are more pronounced in evolutionary ancestors than they are today. They probably aided in grasping and climbing trees as well as tactile perception. There are a range of papillary ridges and their characteristics play an important role in an organism's ability to adapt to its ecological niche. Nowhere is this more evident than on the variety of skin ridges found on some marsupials (Hamrick, 2003). Climbing didelphid marsupials, such as the philander opossum, have prominent and elongated papillary ridges on their digits, which presumably have helped them to adapt to their arboreal habitats. Swimming didelphid marsupials, such as the chironectes, have epidermal projections which extend radially from the rounded papillary ridges on their forelimbs and rounded papillary ridges without epidermal projections in the hind limbs. Chironectes feed under water. The shape of the papillary ridges on their forelimbs presumably helps with the detection of sensory stimulation from each direction.

Another example of skin ridges are those present on dolphins. These become evident at the level of the blow hole and eyes and continue back to the dorsal fin. These circumferential bands are oriented perpendicular to the long body axis. Their spacing is about equal to the distribution of the underlying dermal papillae (Fig. 1D). Their distribution suggests cell lineage may play a role in forming the dolphin integument. These ridges may aid hydrodynamics during swimming. Dolphin skin is sensitive to pressure on its surface. Muscles underlying the skin are believed to produce microvibrations on the skin surface, reducing drag and turbulence and enabling these fleet animals to move quickly through the water (Ridgway and Carder, 1993). The amazing hydrodynamically arranged lines suggest that their formation may be the result of interactions between the skin and the environment. It would be most interesting if we can study the developmental formation of these lines from newborn dolphins.

\section{Pigment patterns}

In addition to the regional specific integument phenotypes and appendage distribution patterns, there are striking color patterns on the integument (Fig. $1 \mathrm{~A}, \mathrm{~B}$ ). Leopards have spots and zebras have stripes. How are these pigmentation patterns determined? Research on pigmentation in fish has shown that as the fish continue to grow new spots are produced between the existing spots (Asai et al., 1999). New stripes also form between existing stripes. Stripes have branch points which migrate over time (Kondo and Asai, 1995). These patterns are consistent with the reaction - diffusion model (Prum and Williamson, 2002). Using zebrafish, investigators have begun to identify some of the molecules that may be responsible for pigmentation patterns. Wildtype zebrafish are striped. Using different mutations of the leopard gene, which affects melanocyte patterns, there was a breakdown of the stripes into spots (Asai et al., 1999). Mutations of genes that affect pigment cell differentiation also affect pigmentation pat- 
terns (Parichy and Johnson, 2001). Striped and spotted pigment patterns are seen in the integument of many species (Fig. 1 A,B).

Migrating striped pigmentation patterns were observed in mice carrying a mutant allele similar to that found in nude mice (Foxn1) (Suzuki et al., 2003). This mutation terminates hair follicle development just after pigmentation begins to accumulate. The terminated hair follicle is then replaced by a new hair follicle which goes through the same process. Pigmentation develops in a broad swath of the skin which separates into two bands migrating in opposite directions. The ensuing patterns resemble those reported by Belousov for oscillating chemical waves (reviewed in Winfree, 1994). It actually reflects the oscillation of hair cycles.

Pigment patterns from two adjacent feathers have similar basic patterns, but the specific patterns can differ slightly. Each of the feathers in Fig. 1E has a striped side and a flecked side. The width of the stripes and spacing between the stripes is fairly well conserved. The patterns on the flecked side are similar but not identical, yet these are adjacent feathers and therefore, the genetics are identical. This finding suggests that genetics sets up a basic pattern, but that lineage and local interactions carry out the patterning process.

\section{Human Blaschko lines}

The lines of Blaschko reflect the distribution of acquired skin diseases and were described over 100 years ago (Fig. 1F; Happle, 1985). In some areas the lines are straight; in others they follow large swirls. Skin diseases have been found to be isolated to half or one quarter of the body. While the mechanism underly- ing the source of these patterns remains unknown, it appears as though they represent somatic mutations which occur in particular lineages of migrating cells from early stages of skin morphogenesis. The migration would be dependent on interactions with neighboring cell lineages and so the general structure of the pattern would be specified, but the specific details of the pattern would be determined by local cellular interactions.

\section{The formation of feather patterns}

The avian integument, an organ made up of epidermis, dermis, appendages, muscles, nerves, etc. have been used as a major model in developmental biology (Sengel, 1976; Yu et al., 2004). The avian integument includes feathers, scales claws, beaks, and combs. They offer distinct patterns at various stages of development and are accessible to analysis using state of the art technology (Widelitz et al., 2003). Although many genes are implicated in the growth and differentiation of the feather buds, little is known about how the discrete pattern of the feather array is formed (Crowe et al. 1998) and how the location, number and size of these repetitive elements are determined (Jiang et al., 1999). In birds, the main appendages are the feathers and the foot scales. In chick embryos, the feather buds arise in a distinct spatial and temporal pattern. The formation of periodic patterns is of fundamental importance in embryonic development. In this review, we will focus on the feathers to describe the pattern formation.

Feather pattern formation is a complex morphogenic phenomenon. Its formation results from a series of inductive events

Fig. 1. Examples of integument patterns. (A) Feather stripes, patches and spots on feathers of a pheasant. There is regional variation in the color of the skin appendage markings. The stripes are brown on the tail feathers and white on the wing feathers. (B) Pigment stripes and spots on a cat. Stripes are present from the neck to the tail with a similar orientation. The stripes on the head have a different rostral-caudal orientation. Some stripes are complete and some are partial. In some regions, stripes break into dots. (C) Fingerprints from the same finger of identical twins. Although genetically identical, epigenetic events during fingerprint formation lead to subtle variations between twins. From Jain et al. (2002). (D) Skin ridges on dolphin integument. Muscles underlying the skin can respond to environmental pressures causing microvibrations which reduce water turbulence, enabling the skin to respond to its environment. The remarkable orientations of the lines imply that the environment has an effect. From Ridge and Carder (1993).

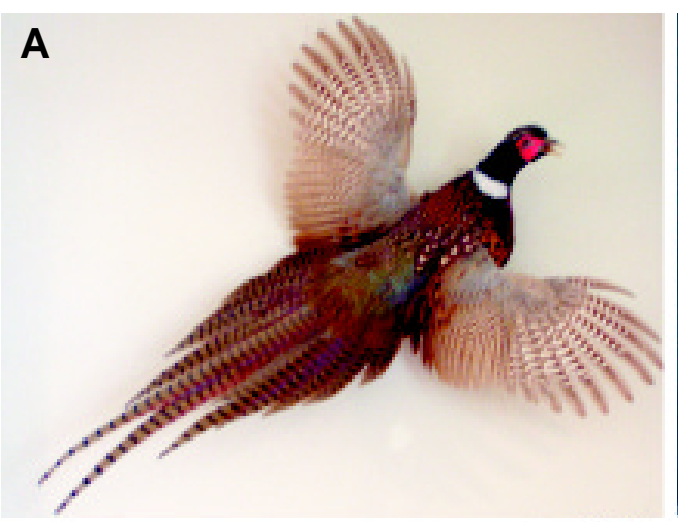

C
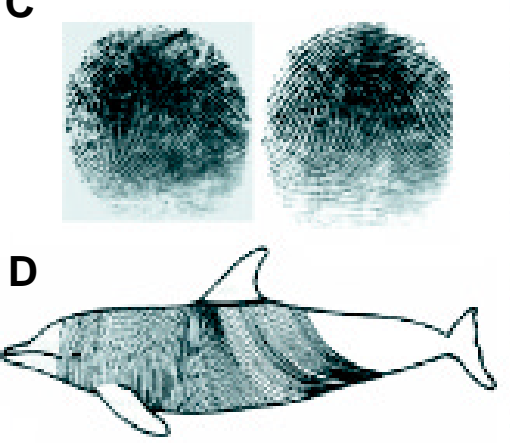

E
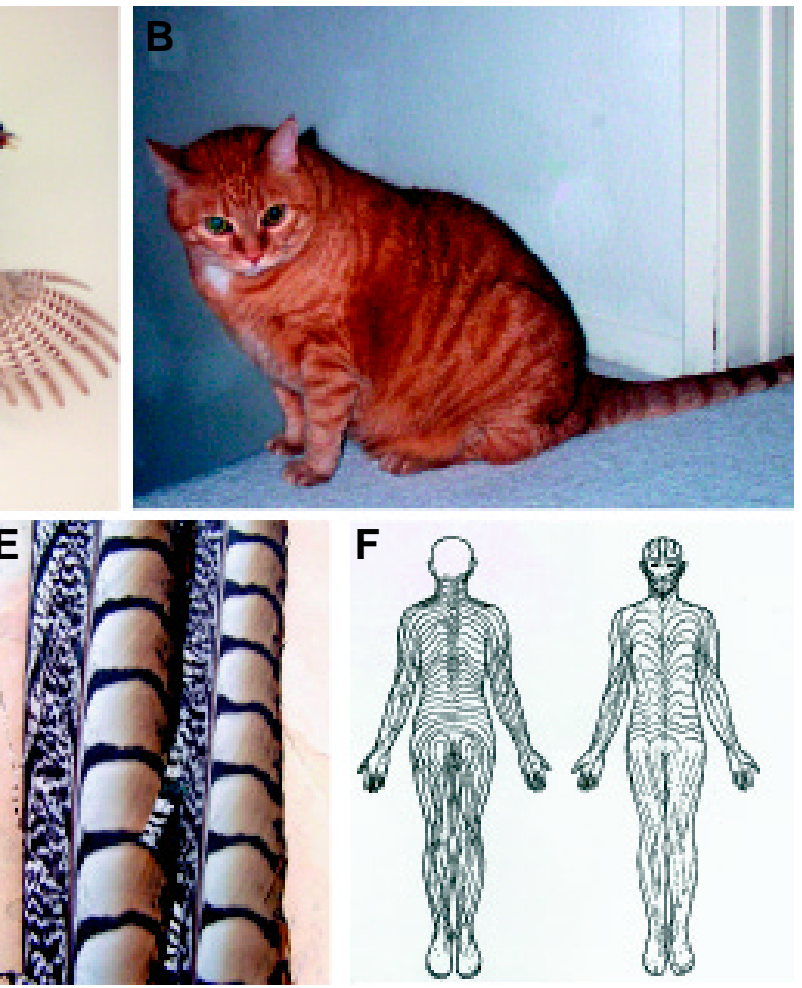

$\mathbf{F}$

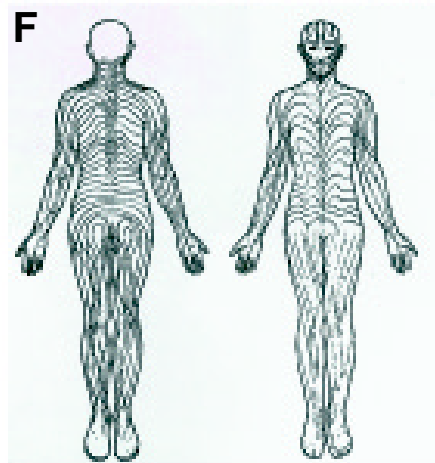

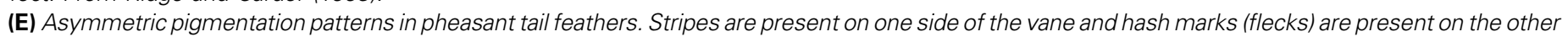

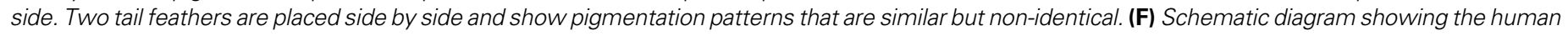

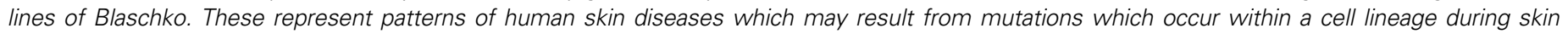
morphogenesis. The nature of these lines is cell lineage based. From Happle, (1985). 

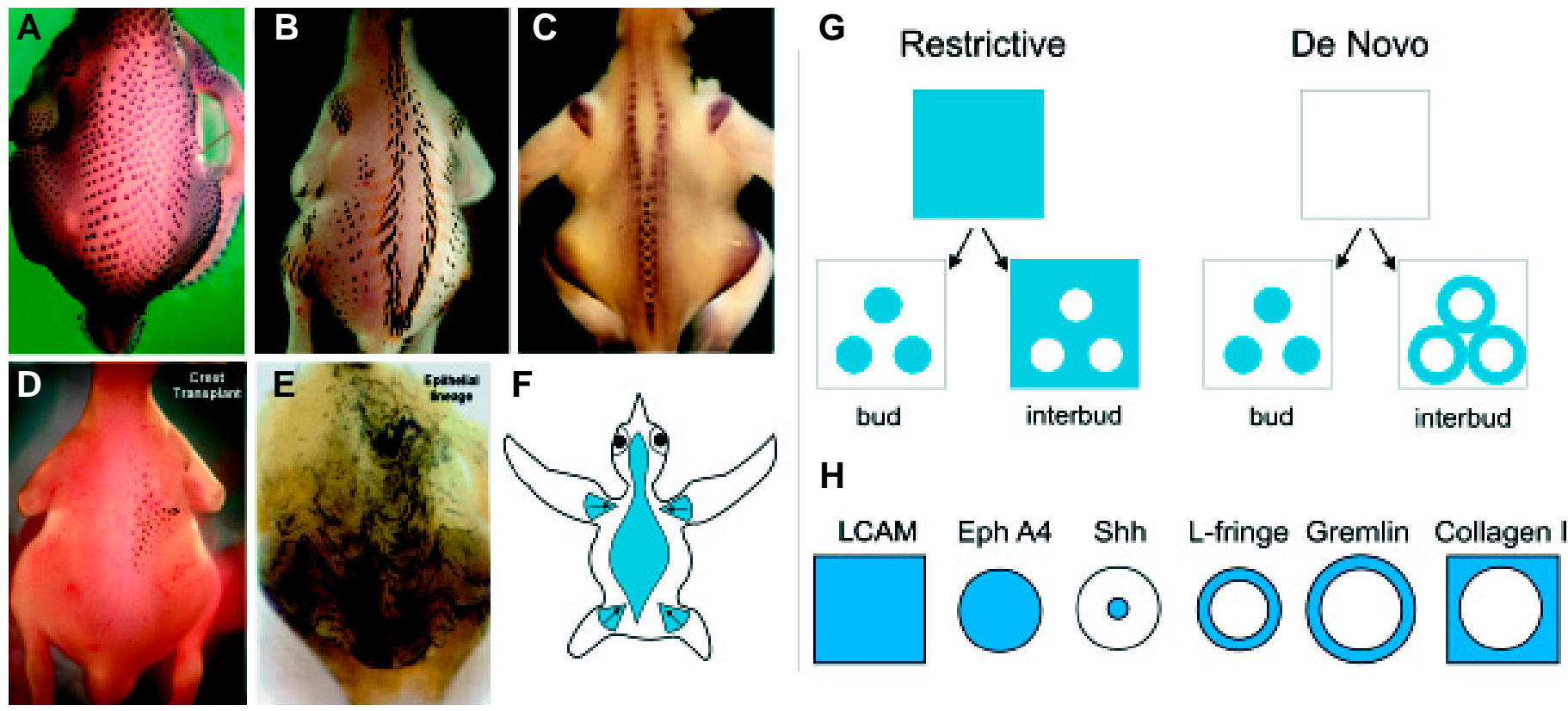

Fig. 2. Different integument patterns can be revealed during feather morphogenesis. (A) Embryonic chicken skin showing feather buds arranged in hexagonal patterns and groups of buds distributed in feather tracts. Buds were visualized by in situ staining for Shh. (B) Feather arrays on the quail. Note the different array pattern between chicken and quail, even though the two species are closely related. The black color is due to melanocytes. (C) $\beta$-catenin marks the initial appearance of feather primordia. During development, the $\beta$-catenin transcripts are first expressed in the whole tract field, before they become restricted to individual feather primordia. Each primordium is then surrounded by a region devoid of $\beta$-catenin expression (Widelitz et al., 2000). (D) Dermatome cell lineages. Quail somites were transplanted to the dorsal midline of chicken embryos. They can be seen to migrate out to populate certain regions of the dorsal lateral trunk. *This patch represents dermal cell lineages migrating out from specific somite regions. (E) Epithelial cell lineage. Epithelial precursor cells near the midline were transduced with LacZ as a lineage marker. The lineage of epithelial cells are distributed in horizontal lines. Note the similarity to the lines of Blaschko in Fig. 1F. From Chuong et al. (1998). (F) Schematic showing feather tracts. Tracts are shown as blue patches. The direction of progressive feather bud formation is shown by the arrow. (G) Modes of molecular expression. Genes are expressed with restrictive (left) or de novo (right) expression patterns. Both modes of expression can form bud or interbud expression patterns. (H) Examples of genes expressed with restrictive and de novo patterns. Expression patterns of L-CAM (Chuong and Edelman, 1985a), Eph A4 (Pateletal., 1999), Shh (Ting-Berrethetal., 1996a), L-fringe (Chen and Chuong, 2000), gremlin (Ohyama et al., 2001) and collagen I are shown.

between the ectoderm and the subectodermal mesoderm derivatives, involving many fundamental cellular processes that are widely studied by basic scientists. The distinct pattern and form of feathers provide an excellent biological case study that can be appreciated by scientists of different disciplines to learn how nature uses different strategies to produce simple forms first, and then integrate them to form complex patterns. The study of the avian integument and pattern formation will lead to a better understanding of basic developmental mechanisms.

In summary, the integument shows a hierarchy of patterning. First, genetics regulates the capabilities of the epithelium and mesenchyme. Second, cell lineage influences the placement of cells, their interactions and local environment which can influence skin appendage phenotype. Labeling the chicken epithelial precursor cells near the spinal column with a LacZ construct demonstrated their migration out in parallel lines perpendicular to the spinal column (Fig. 2E; Chuong et al., 1998) following similar patterns as the lines of Blaschko found in humans (Happle, 1985). Third, a propagation wave is frequently seen in vivo. This must be coupled with periodic patterning in some way, but is driven by a global force sweeping across the integument to set up skin regions (tracts). Fourth, stochastic events which regulate periodic patterning and the distribution of individual skin appendages take place within the tract field.

\section{Macro-patterning: feather tracts}

How does integument patterning occur? Regions of the skin first are separated into distinct tracts (Fig. 2 C,F). Skin appendages within a tract will grow with characteristic arrangements, including their size, shape, length, orientation, etc. which may differ from those found in neighboring tracts. The chicken integument contains about 20 tracts separated by apteric (naked) regions (Mayerson and Fallon, 1985; Lucas and Stettenheim, 1972). Fractionating the integument into domains promotes the formation of diverse structures with expanded functional capabilities distributed with regional specificity.

How are different tracts formed? Tracts form by the migration of epidermal and dermal precursor cells. The precursors for different tracts are derived from different regions. In the spinal tract the dermis originates from the dermatome of the somite. The migration and survival of these dermal precursors involve Wnt1 signaling (Olivera-Martinez et al., 2001, 2002). Once in the spinal tract, these cells proliferate and form a dense dermis which signals to its overlying competent ectoderm to form a feather tract. NCAM expression (Chuong and Edelman, 1985a) is up regulated in the dense dermis. $\beta$-catenin expression marks the competent epithelium (Fig. 2C; Widelitz et al., 2000). Different Wnt members play distinct roles at these different hierarchical levels (Chang et 
al., 2004a). These molecules are not just early markers, but also confer essential properties to these cells (Fig. 3).

\section{Micropatterning: individual feather buds}

Once the tract has formed, when a threshold of dermal cell density in the tract field is reached, a self-organizing process forms periodically-arranged dermal condensations subdividing the originally homogenous feather field into bud domains and interbud domains (Jiang et al., 1999).

The message to form a feather primordium initiates from the dermis. Through epithelial - mesenchymal signaling, dermal condensations followed by epithelial placodes are formed (Sengel, 1976). The placement of dermal condensations determines the location of induced feather primordia (Jiang et al., 1999). In each tract field, the feather primordia form in a relatively specific sequence (Mayerson and Fallon, 1985), reflecting the progressive maturation of the dermis and responding epithelium. Feathers first form a primary row along a longitudinal line. Feathers then form spreading unilaterally (ie, femoral tract) or bilaterally (ie, dorsal tract) and propagate at a rate of roughly 6-8 hours per row (Jung, et al. 1998a, b). The buds in the lateral row usually appear at a level midway between two existing buds of the previous row. Subsequent rows repeat this alternating arrangement. Thus feather primordia appear in an orderly sequence up to the borders of each tract and form a pattern.

\section{Models of pattern formation}

Although repeated patterns are observed in feather formation, the mechanism underlying their formation remains controversial. These repeated structural patterns (Fig. 1A) have inspired scientists to think about how such regular patterns arise. Here we just summarize these models. For more details into the intricacies of patterning models see Held, 1992.

\section{Code based models}

Some scientists thought embryonic patterning might be based upon positional information in the form chemical, physical and genetic characteristics. Cells within an organism presumably have similar genetic characteristics, but their physical and chemical attributes as well as the genes they express, would be influenced by morphogens. These extracellular factors would be distributed throughout the body to provide each spatial entity with a unique molecular signature (Wolpert, 1971). This could be accomplished if there were several diffusible morphogens arrayed as intersecting gradients. Cells could sense the molecular concentration gradients perhaps by discerning higher concentrations on one side than the other or by detecting changes in the concentration as they moved in any given direction. This would then guide these immature cells toward specific routes of differentiation. The discovery of graded and overlapping distributions of homeobox proteins supported the notion of a molecular code.

\section{Template based models}

Some wrote mathematical models to show that sequential formation is important and that the lateral rows are formed using the medial rows as templates (Murray et al., 1983; Oster et al., 1983; Harris et al., 1984; Cruywagen, 1992). In the dorsal skin the initial feather primordia form along the midline. Then through a morphogenetic determination wave feathers sites are established row by row to the lateral margin (Davidson, 1983). This might occur because as cells move they distort the surface of cells and the extracellular matrix over which they move. Since the extracellular matrix is in mechanical equilibrium, cell migration creates mechanical traction forces that extend beyond the regions in direct contact with the migrating cells. This causes locally low/high concentrations of adherent extracellular matrix. The cells will preferentially bind to the highest concentrations of extracellular matrix and hence an extracellular matrix gradient is interpreted as
Fig. 3. A model for feather periodic patterning involving reaction-diffusion and competitive equilibrium. (A) Through experimentation, some molecules are found to enhance feather formation (named activators) and some suppress feather formation (named inhibitors). Exemplary activators (FGF 4) and inhibitor (BMP 4) are shown. PMA increases the size of the interbud domain (inhibitor of bud formation) whereas Forskolin decreases the size of the interbud domain (activator of bud formation). (B) Data show that both activators and inhibitors of bud formation are located in the bud region, not in the bud and interbud, respectively. The activators induce both activators and inhibitors, while the inhibitors suppress the activators. Some growth factors promote or suppress interbud formation. Examples include Shh (Ting-Berreth et al., 1996a), FGF (Widelitzet al., 1996; Song et al., 1996; Jung et al., 1998), PKA (Noveen et al., 1995b), follistatin (Patel et al., 1999), BMP (Jung et al., 1998), Delta-1 (Crowe et al., 1998), retinoic acid (Chuong et al., 1992), EGF (Atit et al., 2003), PKC (Noveen et al., 1995b), Wnt 7a (Widelitz et al., 1997). These results favor the involvement of a reaction diffusion mechanism (Turing, 1952; Nagorcka and Mooney, 1985; Moore et al., 1998; Jiang et al., 1999).
A

A FGF

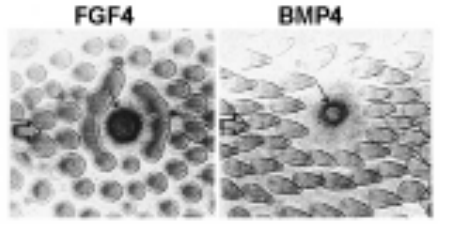

Bud Bud Activator Inhibitor
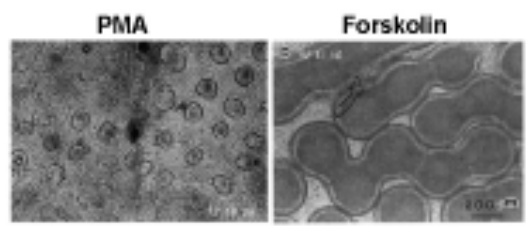

$B$ Shh
FGF 1, 2, 4
PKA
Follistatin Follistatin \begin{tabular}{|l|}
\hline BMP 2, 4, 7 \\
Delta-1 \\
Retinoic Acid \\
\hline
\end{tabular} Interbud Promoter Interbud Suppressor

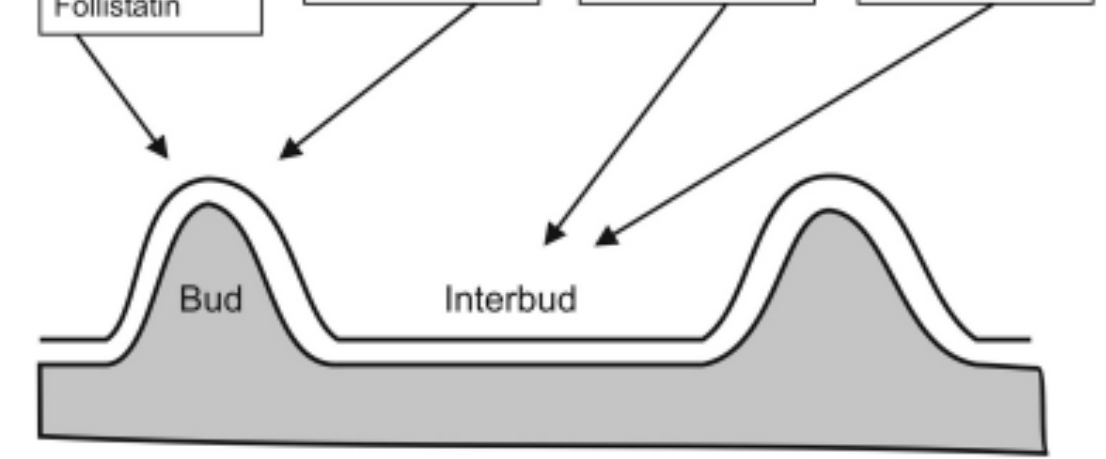


localized pockets of cells. This further deforms the extracellular matrix and places tension at distant sites which guides additional cells toward the cell cluster and toward the sites of future cell clusters posterior and lateral to the initial feather primordia. Hence existing periodic patterns with specific intervals can act as a template and direct the formation of future periodic patterns.

\section{Determination wave models}

These models are based on a signal released from an organizer region which propagates. The signals can be in the form of chemicals passed by diffusion or by direct contact from cell to cell. In some models the cell state oscillates in a constant state of flux, but becomes fixed by the determination signal (clock and wavefront model; Cooke and Zeeman, 1976). This can only be used to explain the one dimensional formation of somites (Pourquie, 2003). Many of these models incorporate the concept of a competence wave where there is a narrow response window in which tissues can respond to the determination wave.

\section{Equilibrium based models}

A reaction - diffusion mechanism (Turing, 1952; Giere and Meinhardt, 1972; Nagorcka and Mooney, 1985; Moore et al., 1998; Jung and Chuong, 1998) has been used to describe periodic patterning in inanimate objects as well as in living systems. This mechanism can account for pattern formation through self-organization. In reaction - diffusion, random fluctuations in molecular expression become amplified to form peaks and valleys. These however are unstable. The peaks and valleys were later postulated to be maintained and propagated through chemical interactions or mechanical forces. Meinhardt and Gierer (1974, 2000) proposed that some molecules distributed by a reaction - diffusion mechanism might stimulate the production of the periodic structures (activators) while some suppress their synthesis (inhibitors) through auto - and cross -catalysis. Activators also have the ability to further stimulate the production of activators as well as induce the production of inhibitors. Activators were postulated to act upon a narrow band of competent epithelium (Ede, 1972). Inhibitors suppress the production of activators, leading to lateral inhibition. Lateral inhibition was first suggested to regulate the patterning of bristles by Wigglesworth (1940). This model was applied to feather patterning in which inhibition would produce a circular inhibitory zone around each forming feather bud (Ede, 1972). Lateral inhibition has since been found in Drosophila sensory bristle patterning. Here, cells capable of forming neurons express Delta which binds to its Notch receptor on neighboring cells and leads to a block of their further neurogenesis (Collier et al., 1996; Artavanis-Tsakonas et al., 1995). Generally, it has been found that activators have a narrower distribution than inhibitors. The relative concentration of activator versus inhibitor at any given location determines whether that region becomes the repeated unit or space between the units.

If the reaction - diffusion mechanism is at work, it is possible that all of the theories put forth are true to a degree depending on which model system is used to test them. Starting from a pool of equivalent cells, the reaction - diffusion model fits the observation. The other type is a set of rules categorized as cellular automata (Wolfram, 2002). Cells change state depending on the states of its neighbors. It is also based on randomness and stochastic and can generate different unexpected patterns. However, it lacks the movable cells and diffusible substances that are more close to biological questions (Shen et al., 2004). Our Digital Hormone Model tries to integrate these important ingredients (see ahead).

In a post-induction skin explant in which initial patterns are set, mechanical or chemical signaling can then take place and set up template based mechanisms or positional information deposition. These mechanisms may be right, but they describe later phenomena, not the initial patterning events.

\section{Experimental data on feather pattern development}

\section{Classical data}

Which of the above models fits the experimental data? The border of a feather tract is dynamic. A tract may already be formed and stabilized on one edge but still progressing on another front. When the spinal cord and somite were removed surgically or the embryos were treated with glucocorticoid, the spinal tract was interrupted and the femoral tract enlarged in compensation (Zust, 1971; reviewed in Sengel, 1976). The fusion of femoral tracts or the fact that scapular tracts became adjacent following the absence of a part of the spinal tract was studied by Olivera-Martinez et al., 2001. This work shows that embryonic epithelial cells have the ability to become part of either tract or apteric regions and that the "territory" of feather tracts are plastic. That is they are not premapped strictly but can be re-adjusted depending on wounding or developing conditions. Thus, the apteric zones that form between two tracts is the result of competition and balance, not a predetermined border.

Feather patterning also has been studied using skin explant cultures in classical studies and epithelial - mesenchymal reconstitution assays (Jiang et al., 1999). These experimental models provide an opportunity to modify experimental factors in order to examine the possible mechanisms regulating feather tract formation

To determine where the organizer was during regulating feather pattern formation, longitudinal incisions were made at three locations in skin explant cultures. The first was along the first lateral row of feathers. The second excised the mid-dorsal initial row entirely. The third was along the mid-dorsal line and bisected the mid-dorsal rudiments. When the mid-dorsal row was either eliminated or damaged, explants made from younger skin reorganized and formed a feather pattern. This indicates that the skin was capable of selforganizing into feathers at a location corresponding to a primary morphogenetic zone. This morphogenetic wave then spreads to lateral regions as development progresses. The observed hexagonal feather pattern was not predetermined since the position of each feather rudiment was not pre-established (Sengel, 1978; Linsenmayer, 1972; Novel, 1973). Rather, all dermal cells could participate in the construction of a condensation.

How do dermal cells form an organized pattern during development? Dermo-epidermal recombination cultures were used to analyze the influence of the epithelium on dermal condensation formation. The epidermis and dermis were separated and then replaced aligned at $90^{\circ}$ or $180^{\circ}$ with respect to each other. In explants whose epidermis and dermis maintained the original alignment, new feathers formed along the midline and then subsequent rows formed lateral to the primary row (Novel, 1973). However, when the components were aligned after $90^{\circ}$ or $180^{\circ}$ rotation the formation of the new primary row depended upon the stage of the epidermis and the dermis. If recombinations were 
performed using material from early developmental stages (E6.5) the epithelial - mesenchymal interactions are reset and the primary row forms along the orientation of the dermis. Hence signals from early stage dermis can determine the location of the feather primordia at non-predetermined locations. However, the epidermis determines the anterior-posterior polarity. Similar results were shown in studies recombining feather forming epithelium and mesenchyme from E7 chicken embryos (Chuong et al, 1996). At later stages (E7.5), the primary row was already established and was maintained relative to the midline of the epidermis. Recombinations of scale forming epithelium and mesenchyme from E10-13 chicken embryos also could induce skin appendages whose shape was determined by the dermis but the overlap was determined by the epidermis (Sullivan, 1972).

The capabilities of the epithelium and mesenchyme were further tested using hetero- animal class recombination experiments involving reptiles vs. birds, reptiles vs. mammals and birds vs. mammals (Dhouailly, 1975). Here chick dorsal dermis induced scale primordia or hair buds from the lizard or mouse epidermis respectively, but they are distributed according to the feather pattern. Chick scale forming dermis induced scales and hair follicles from the lizard or mouse epidermis respectively, but they are arranged like avian scales. Dorsal mouse dermis induced large and small scales, feather filaments or hair follicles from chicken and mouse epidermis, but they are in hair distribution pattern. The upper lip mouse dermis induced enlarged scales, feather filaments, or whisker follicles distributed in a typical vibrissa pattern. Dorsal and ventral lizard dermis induced a dorsal and ventral arrangement of scales, respectively. Only lizard dermis could not effectively induce skin appendage patterns from chicken or mouse epidermis. These experiments demonstrated that skin appendage patterning was determined by the dermis and the message can be "understood" among birds, mammals and reptiles.

\section{Restrictive versus de novo modes of molecular expression}

We now know that tissue interactions are mediated by underlying molecular interactions. Changes in molecular expression often precede the appearance of physical changes. Several laboratories have sought to establish molecular expression patterns within the developing feather tracts and feather primordia using in situ hybridization and immunostaining (Chuong et al., 1996; Jung etal. 1998a, Noramly and Morgan, 1998; Crowe et al., 1998; Viallet etal., 1998). In general two expression patterns have been identified. Some molecules are initially expressed at moderate levels throughout a feather tract and the expression is later up regulated within feather primordia and down regulated in interprimordia or vice versa. This expression pattern is termed the restrictive mode. Other molecules are expressed at later developmental stages, but appear within structures that have already formed. This expression pattern is termed the de novo mode. Wnt-7a, follistatin and $\beta$-catenin are among the molecules expressed in a restrictive mode (Fig. 2H; Widelitz et al., 1999; Widelitz et al., 2000; Patel et al., 1999). Sonic hedgehog, Delta1, Notch-1, L-fringe, R-fringe and Eph-A4 are expressed following the de novo mode (Fig. 2H; Ting-Berreth and Chuong, 1996a; Chen et al., 1997; Crowe et al., 1998; Viallet et al., 1998; Patel et al., 1999; Chen and Chuong, 2000). What roles do these molecules play in feather formation? How does the expression mode influence the effect of molecules?

\section{Positive and negative regulators of periodic patterning}

Retroviral mediated gene expression has been employed to test molecular function in vivo. The replication competent avian sarcoma virus (RCAS) has been an effective vector for the delivery of genes for ectopic expression in living chickens. Some proteins are thought to function as morphogens in developing embryos by forming concentration gradients. Concentration gradients can be mimicked from purified proteins by applying them to tissues from coated beads (Fig. 3A). In this way the tested agents are released over time and form a concentration gradient with the highest concentration present at the location of the bead. These tools have been used to test the function of several molecules. Some molecules have been found to enhance the formation of feather buds and are termed activators. Some suppress the formation of feather buds and are termed inhibitors (Fig. 3B; Noveen et al., 1995a,b; Ting-Berreth and Chuong, 1996a, b; Noramly and Morgan, 1998; Crowe et al., 1998; Viallet et al., 1998; Song et al., 1996; Widelitz et al., 1996; Patel et al., 1999). Sonic hedgehog, FGF4, Noggin, follistatin, and others have been found to serve as activators. BMP2, BMP4, activators of protein kinase $C$ and others function as inhibitors.

A balance of activator and inhibitor activity must regulate periodic patterning (reviewed in Held, 1992), as was found for lung morphogenesis (Hogan, 1999). One might expect that the activators are expressed in the feather primordia, while the inhibitors are expressed in the interbud regions. This was not the case. Activators and inhibitors were both expressed within feather primordia (Jung et al., 1998). Hence, it is unlikely that feather patterning results from prepatterning. The activator and inhibitor expression patterns are more consistent with a model based on the reaction diffusion model (Turing, 1952; Giere and Meinhardt, 1972).

These activators and inhibitors follow the tenets of reaction diffusion. Activators (FGF4 and Shh) induce the expression of inhibitors (BMP-2, -4), while inhibitors (BMP-2, -4) suppress the activators (FGF4 and Shh) (Jung et. al., 1998; Jiang et al., 1999). Furthermore, follistatin, an antagonist of BMP, was also induced within the feather primordia (Patel et al., 1999). By implanting coated beads to embryonic skin, we demonstrated that activators have the ability to induce both activators and inhibitors, while inhibitors can block the release of activators (Jung et al., 1998).

\section{Self-organization and competitive equilibrium operate at the cellular level}

\section{Reconstitution of feather buds}

Since many of the activators and inhibitors which affect pattern formation are expressed in a restrictive mode, it is very important to examine their effects using an experimental system in which all cells have the same probability of becoming primordia or interprimordia, and in which the size and number of feather primordia are not irreversibly predetermined. A model that starts from a homogeneous state is needed. After trying several approaches, we developed an in vitroreconstitution system (Fig. 4A, Widelitz et al., 1999; Jiang et al., 1999) in which all mesenchymal cells are reset to an equivalent state and have the same probability to become primordia or interprimordia. In this assay, the epithelium of stage 29-35 chicken embryo dorsal skin is separated from the mesenchyme (Fig. 4B). The mesenchyme is then dissociated to form a single cell suspension (Fig. 4C). This 
disrupts all prior cellular interactions and resets molecular expression to a primitive state. The mesenchymal cells are centrifuged and re-suspended to high cell density suspension. The cells are then plated on a culture insert dish and allowed to form aggregates. The epithelium was then placed on top of the mesenchyme.

Using this model, several surprising findings were revealed. 1) Feather primordia could still form (Fig. 4D), showing that periodic patterning of feather primordia is a self-organizing process, and the information required for patterning is sufficiently stored in dissociated and scrambled competent mesenchymal cells. Neither pre-existing order nor cues from the extracellular matrix are required for patterning and the cells can regenerate this information. 2) All the feather primordia appeared simultaneously at 24 hours, rather than the sequential pattern seen in vivo. This suggests that neither a primary row nor the sequential propagation is a prerequisite for the periodic pattern formation of feather buds. It is an additional global event superimposed on the local periodic patterning process in vivo. 3) To test whether the feather primordia mesenchyme has memory or is different to start with, we labeled the primordia mesenchymal cells with $\mathrm{Dil}$ and then performed the reconstitution procedure. After reconstitution, the Dil positive cells were randomly distributed within and outside the primordia, suggesting that, in this model, all competent mesenchymal cells are indeed reset to an equivalent state and have the same probability of becoming either part of the primordia or part of the interprimordial regions. 4) To test whether the placode is the primordia organizing center, we labeled placodal cells with Dil and performed the procedure. If the placode is organizing the primordia, all the newly formed primordia should be under the original, Dil labeled placode. The results showed that new primordia can form without regard to the position of the original placode.

Those findings uncoupled periodic patterning from sequential propagation in vivo. The problem with some of the previous models may not be that they are wrong, but that they used experimental models that did not represent the most initial homogenous state. Disparate position information (Wolpert, 1971) and differential adhesion (Steinberg, 1975) are likely to play a role in development, but these apply only after molecules expressed in the de novo mode (see above) are established.

Although feather buds formed simultaneously in the reconstituted skin explant experiments described above, during normal development a wave of morphogenetic activity moves unidirectionally or bidirectionally from a primary row. Hence, it appears that a morphogenetic wave is superimposed on the inherent ability of cells to self-organize. By staining for $\beta$-catenin it was found that feather primordia once formed, initially were surrounded by a ring lacking $\beta$-catenin expression (Fig. $2 \mathrm{C}$ ). When two adjacent feathers formed the distance between them was equivalent to a single ring. As development progressed and the skin expanded, the size of the space between the feather buds increased until it equaled the space of two $\beta$-catenin negative rings (Widelitz et al., 2000).

\section{The number, size and position of feather buds}

While periodic patterning processes can produce individual primordia elements, we wondered how the size, number, and spacing of feather primordia were regulated (Jiang et al., 1999). The feather reconstitution model offered an opportunity to test this, because it allowed us to recombine a fixed sized epithelium with different numbers of mesenchymal cells. When increasing numbers of mesenchymal cells were used, we could expect either the same number of primordia with gradually increasing size or increasing numbers of primordia with a constant size (Fig. 4E). The results showed that for mesenchymal cells derived from the same region, the feather primordia were always the same size. The way the number of primordia increased also provided us with insight to feather patterning. At low numbers of mesenchymal cells, no primordia formed. As mesenchymal cells gradually increased, more feather buds formed, each with a lateral inhibitory zone. At lower density, primordia were distributed at random, not as aborted rows of a hexagonal lattice. As more cells were used, the number of primordia increased until it reached a maximal packing density, and feathers appeared to be arranged in a hexagonal pattern (Fig. 2A). However, this hexagonal pattern is a result of maximal packaging, not a consequence of preset molecular codes or positional values.

The size of the feather primordia can be different from one feather tract to another. How does this happen? The reactiondiffusion model predicts that the ratio of activator and inhibitor will determine the size (the diameter) of the element (feather primordia). In this case, the ratio is dependent upon the concentration of activator or inhibitor ligands, the number of their receptors, and the number of downstream signaling molecules induced by their activity. If this model is correct, we should be able to modulate the size of primordia by changing these parameters (Fig. 4G). Indeed, when the number of BMP receptors is increased, feather primordia became smaller. And when Noggin, a BMP inhibitor, was increased in the system, feather primordia became bigger (Fig. 4F; Jiang et. al., 1999).

Thus periodic patterning within a feather tract field is a selforganizing process leading to the formation of individual feather primordia with characteristic size and numbers, depending on the properties of the cells (number of ligands, receptors of signaling activators or inhibitors) and the environment. It is a process where the competent mesenchymal cells compete for the available and limited piece of the competent epidermis. The final stable pattern results from competition and equilibrium and is not based on a predetermined code. The size and number of each element can be modulated by altering the parameters that affect the reaction diffusion and competition processes.

\section{Cell adhesive interactions}

Furthermore we have examined the cellular events occurring during the restrictive phase and found that the most initial events may be driven simply by cell adhesion when the mildly adhesive cells reach a threshold density. We found that the homogenous mesenchymal cells then form many small cellular aggregates (1025 cells). These microaggregates can condense into larger aggregates, but the adhesions are reversible at this stage and the aggregates are unstable. As condensed aggregates get bigger, the above activator/inhibitor mechanism is initiated and the formation of the dermal condensations is consolidated. These condensations then can send the "1st dermal message" to the epidermis to form the placode (Fig. 5E; Dhouailly, 1977; Hardy, 1992; Chuong et al., 1996). 

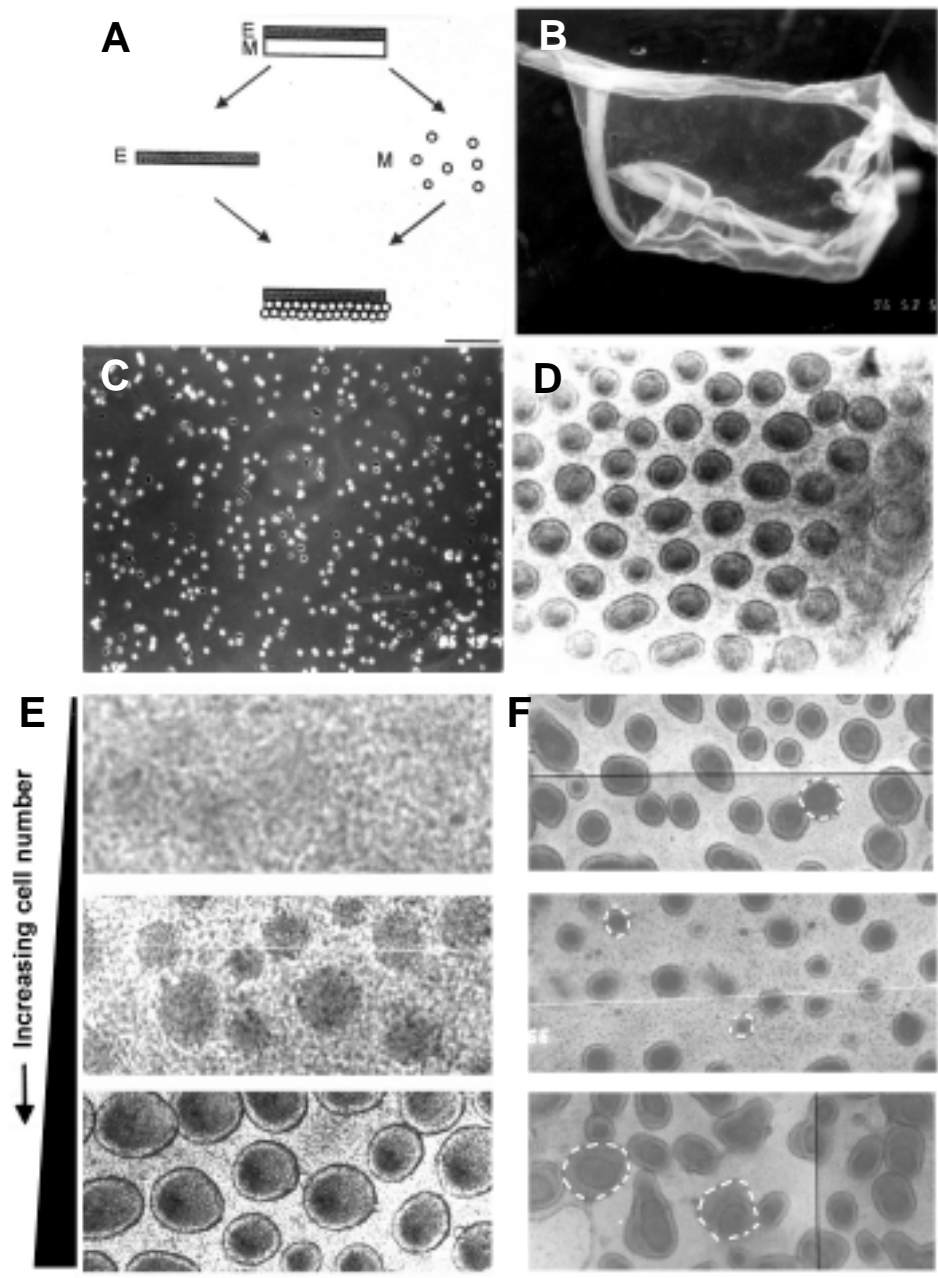

Same hormone profile,

but different cell density
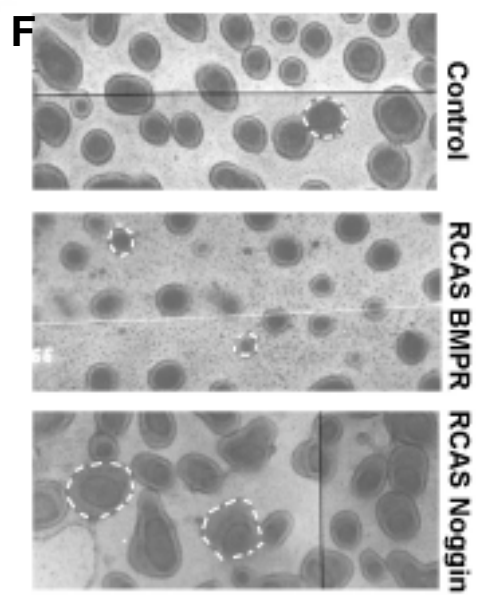

Same cell density but

different hormone profile
G

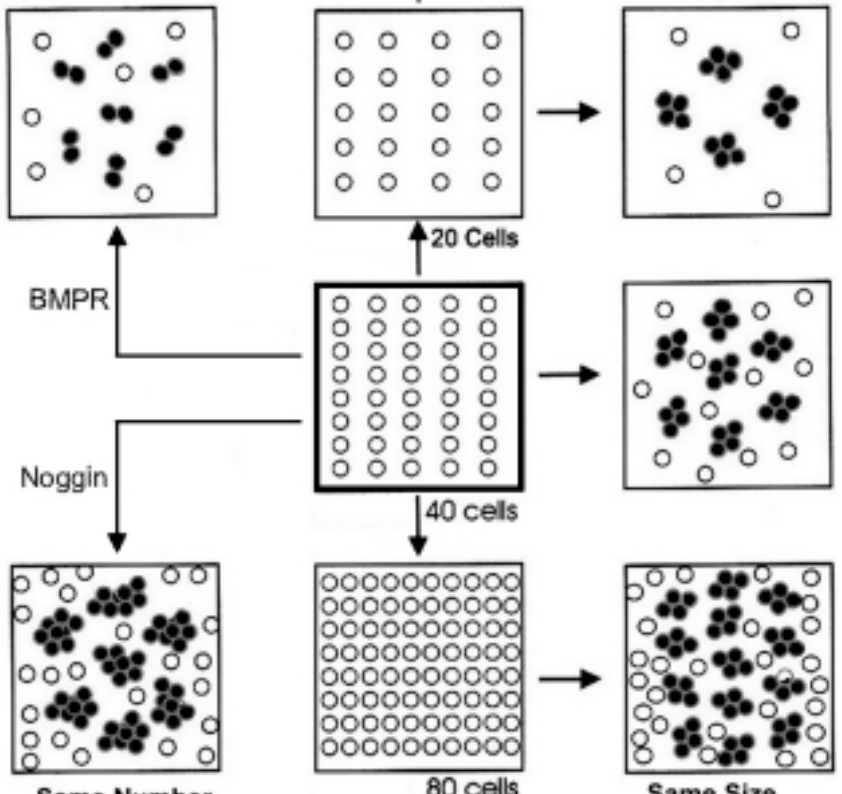

Same Number

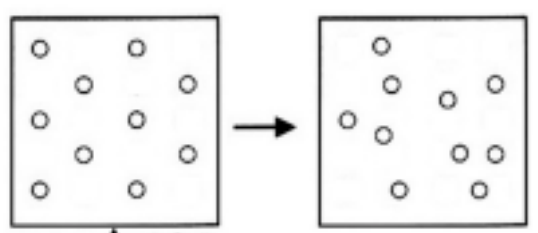

$\uparrow 10$ Cells

Same Size

Fig. 4. A novel reconstitution assay which allows the study of periodic pattern formation from the ground state. (A) Embryonic day 6 chicken skin was dissected. (B) Epidermis (shown) was separated from the mesenchyme. (C) Mesenchyme was dissociated into single cells. (D) Mesenchymal cells were recombined with epithelium and plated. In 3 days, they self-organize into many feather buds simultaneously (Jiang et al., 1999). (E) Using the reconstitution model, we tested the relationship using a fixed size of epidermis while increasing the number of competent mesenchymal cells. Logically, either the number of buds or the size of the feather primordia could increase. We found that, using skin from a certain region, the size of the feather primordia is constant. At low density, buds did not form. At higher cell density, feather primordia started to appear randomly. The density of feather primordia gradually increased until they reached the highest packing density, which yields the hexagonal patterning (Jiang et al., 1999). Our results show that it increased the number of feather buds. We propose that competent cells are first distributed homogeneously in the field. These cells adhere randomly and this adhesion is reversible. When these small unstable aggregates surpass a threshold density, they become stable dermal condensations. (F) The size of each dermal condensation is dependent on the ratio of activator molecules (noggin, FGF, Shh, etc) to inhibitor molecules (BMPs). A higher activator to inhibitor ratio allows the formation of larger sized feather buds, while a higher inhibitor to activator ratio favors the formation of the interbud region (Jiang et al., 1999). (G) Schematic diagram showing that increasing mesenchymal cell number increases feather number at a constant size. The size of feather buds is influenced by activators (Noggin) and inhibitors (BMP).

For this to happen, cells must express cell - cell adhesion molecules that recognize and specifically bind to each other. Such molecular recognition and binding bring cells together during development to form specific organs. Several families of cell adhesion molecules have been localized in the developing chick skin. Although their exact functions during skin and feather development are not completely known, some intriguing information has emerged in recent investigations. NCAM and cadherins are cell - cell adhesion molecules which have been found to play important roles in feather patterning (Fig. 5A; Jiang et al., 1999;
Noramly et al., 1999). Unstable mesenchymal cell aggregates initially form, but once aggregates of $10-20$ cells appear they stabilize express higher levels of NCAM and attract neighboring cells and cell aggregates (Fig. 5B). Regions surrounding the aggregates stop expressing NCAM (Fig. 5C). Cell-substrate binding is also important for feather formation. Cell attachment to extracellular matrix often requires integrin binding to laminin or fibronectin, adhesion proteins found localized in extracellular matrix and through molecular cascades may trigger focal adhesions or contacts. 

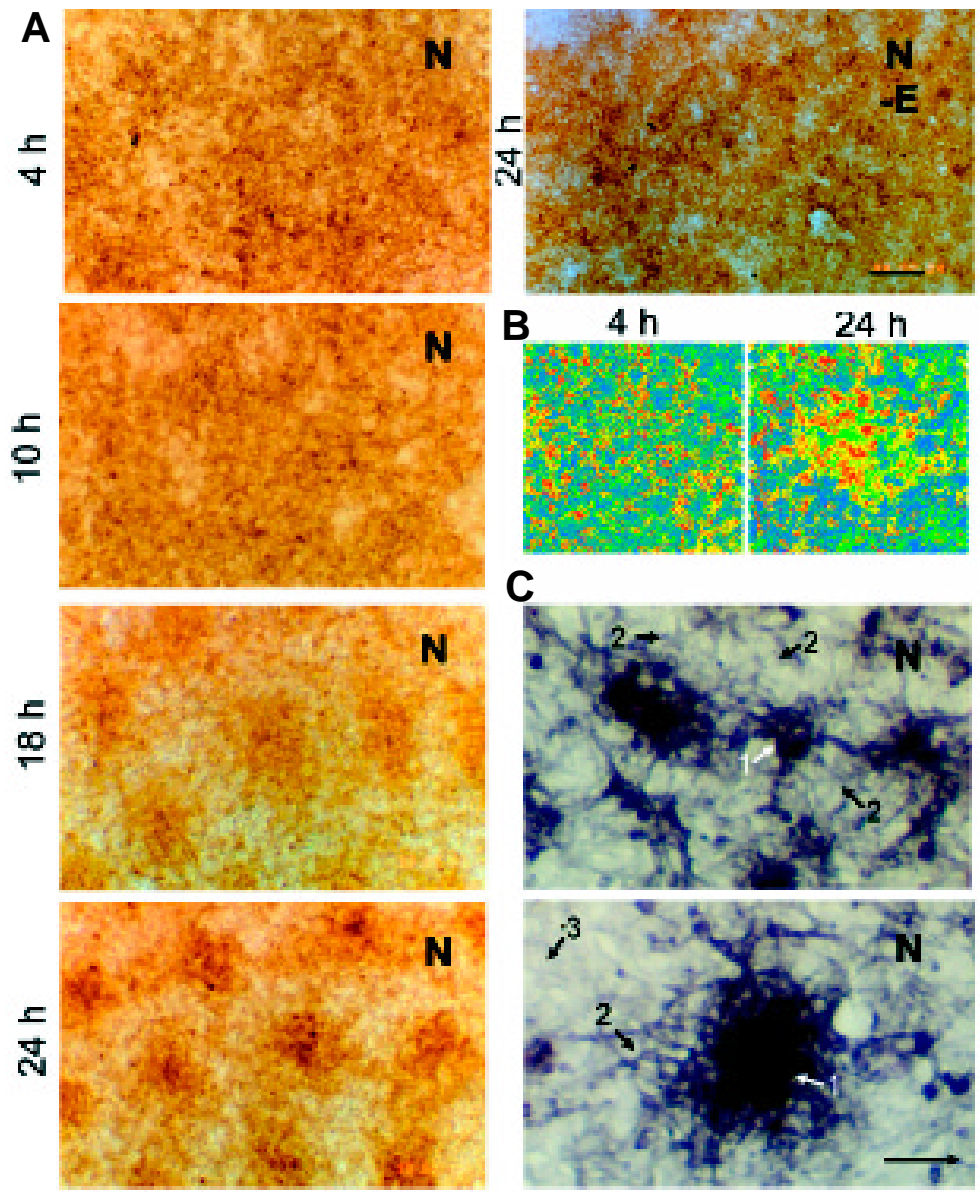

E

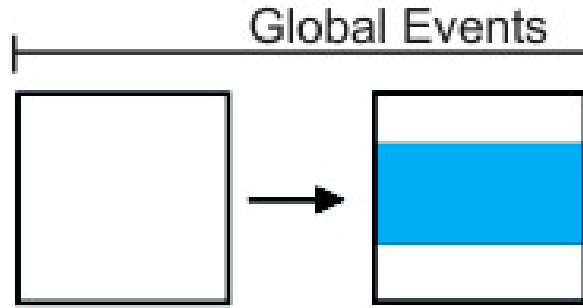

Formation of a tract field
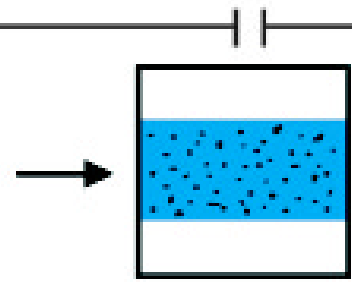

Formation of
Microaggregates

D

Fig. 5. Cell adhesion molecules act as mediators of patterning. (A) Immunostaining for NCAM in reconstituted explants or in dissociated mesenchymal cells (N-E) after 4, 10, 18 and $24 \mathrm{~h}$. in culture. Scale bar, $200 \mu \mathrm{m}$. (B) Pseudocolor and high power views. (C) NCAM was expressed at moderate levels throughout the cultures and was upregulated in cell aggregates by $18 \mathrm{~h}$. (arrow 1), but was expressed at basal levels in lower density aggregates (arrow 2) and not expressed where cells remained aggregate-free (arrow 3). (D) Schematic drawing shows that cells are initially attached to their substrates, but through extracellular matrix molecules, cell-cell adhesion becomes greater than cell-substrate adhesion leading to cell condensation formation. (E) Hence, during feather formation, global events help to form the tract field. Random unstable cell aggregates begin to form in the mesenchyme. Local events now begin to dominate the feather forming processes. Stable aggregates form and signal to the overlying epithelium to form a placode. This induces alterations of molecular expression. Through a reaction - diffusion mechanism, these molecular expression patterns are intensified into periodic patterns which shape and consolidate the forming feather primordia.
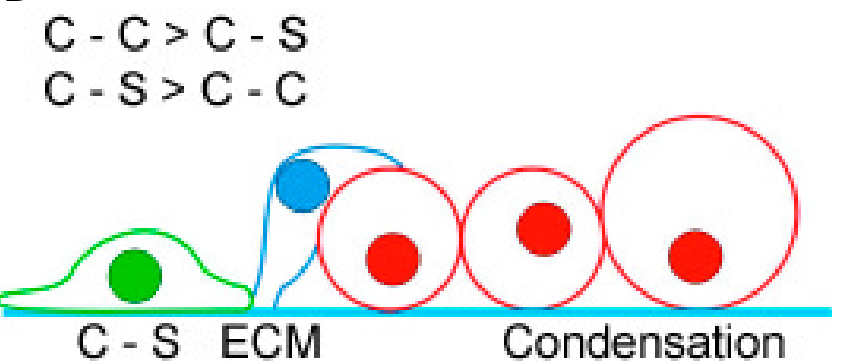

Local Events

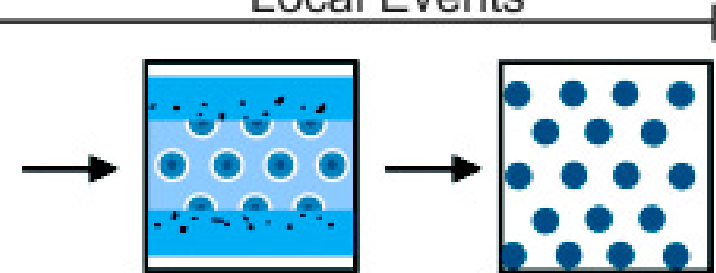

Restrictive and de novo molecular expression modes

Formation of an individual primordium field

\author{
Phase of \\ Establishing \\ Competence (E) \\ and Cell Density (M)
}

\section{Phase of \\ Random \\ Aggregation (M)}

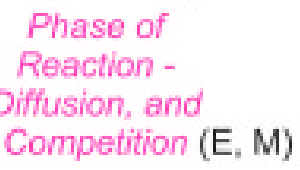

\author{
Phase of \\ Consolidating \\ Periodic \\ Patterns (E, M)
}

\section{Digital Hormone Model}

\section{The basics}

From these studies we can appreciate that at the level of cell interactions, a set of rules different from strict genetics rules are in operation. While the information to form feathers is coded in the avian genome, the final arrangement is not directlycoded in the genome. The genome specifies combinatorial protein profiles that are expressed on the cell membrane, as well as the extra-cellular micro-environment made of diffusible signaling molecules and matrix molecules. At this level, cells sense and interpret the environment and then make a response to it. It is not as precise as genetic control in which information flows from the top down and aberrant mutations will be eliminated. The cell interactions are now governed by physico-chemical rules that flow from the bottom up (local), stochastic, and probabilistic. The reaction finally reaches an equilibrium, and the pattern we observe is this equilibrated state, not due to coordinate information directly encoded in DNA. In invertebrates or other species, patterning may be under dominant genetic control. At least in feather bud 
formation and likely in many other higher levels of organization, the epigenetic rules appear to have more control.

How can we describe cell behaviors at this level? Turing has proposed the reaction diffusion mechanism in which two factors interact locally and diffuse randomly to form distinct patterns (Turing, 1952) Giere and Meinhardt developed it further to interpret biological patterning (Giere and Meinhardt, 1972; Meinhardt and Gierer, 1974, 2000). Our feather reconstitution data are consistent with these theories. At the beginning of reconstitution, cells are reset to a homogeneous state (Fig. 6A). Whether a cell becomes part of a cell cluster or remains dissociated is due to competitive equilibrium. This equilibrium is modulated by adhesive properties of cell membranes (a sum of cell adhesion molecules on that cell), activity of activators/inhibitors (concentration of ligands and their antagonists, the amount of receptors on that cell), properties of extracellular matrix (diffusion rate of signaling molecules, adhesiveness for cell migration), and the dimension of the field. The sum of these factors in an equilibrated state produces small dots, large dots, or stripes. The system is self-organizing because the cells will start to reorganize themselves once dissociated and placed in culture (Fig. 4). The system is plastic, since the size and number of cell clusters can be changed by adjusting variables (ratio of activators/inhibitors, and available cell numbers, respectively). The system is not pre-coded since the final patterns of replicate samples are similar but non-identical. The system is random since in replicate samples different cells are incorporated into cell clusters.

While we know these principles are involved, we do not have a model in which cells can follow a set of basic principles and self-organize into patterns. To have a model that closely simulates biological phenomena and has molecular activities/cellular events identifiable for its parameters, we have developed the Digital Hormone Model (DHM) (Fig. 6B; Shen et al., 2004; Shen et al., 2002). Here the hormone indicates the local extra-cellular signaling molecules. This model consists of the basic activator/ inhibitor concept (Meinhardt and Gierer, 1974), but also builds upon cell adhesion and cell density as essential elements. DHM consists of three basic components: 1) a self-reconfigurable set of cells, 2) a probabilistic function for individual cell behavior, and 3) a set of equations for hormone reaction, diffusion, and dissipation. Here we describe the model in non-jargon language. A more detailed version written in formal engineering language is in the appendix.

1) A self-reconfigurable set of networks. In the feather scenario, this is a set of competent cells participating in the morphogenetic process. On the surface of each cell, there is a combination of adhesion molecules that endows that cell with a certain level of adhesiveness (or connectors, in the engineering terms). This adhesiveness can change dynamically. All cells start from a homogenous average value, but they then increase or decrease values following the rules described below. A cell communicates with its neighbors. Through these local interactions, cells can generate hormones or propagate hormones, adhere or de-adhere. The configuration (arrangement of all the cells) keeps on changing. It finally reaches a stable condition and this final configuration is the pattern we observe.

2) A probabilistic function for individual cell behavior. The choice of action to be taken by a cell is based on a probability function which is dependent on four local factors: the cell adhesiveness, the hormone concentration, the receptor activation, and the values of local variables. The probability function is local and homogenous for all cells. In the model, the probability function is programmed by the system initially, but it can change dynamically over time. Eventually, it influences the global behavior of cells within the field and can be used to predict and analyze global patterning.

3) A set of equations for hormone reaction, diffusion and dissipation. Following Turing (1952) and Giere and Meinhardt (1972), we assume in the mathematical description that hormone reaction and diffusion occur through a two-dimensional medium, although analo-

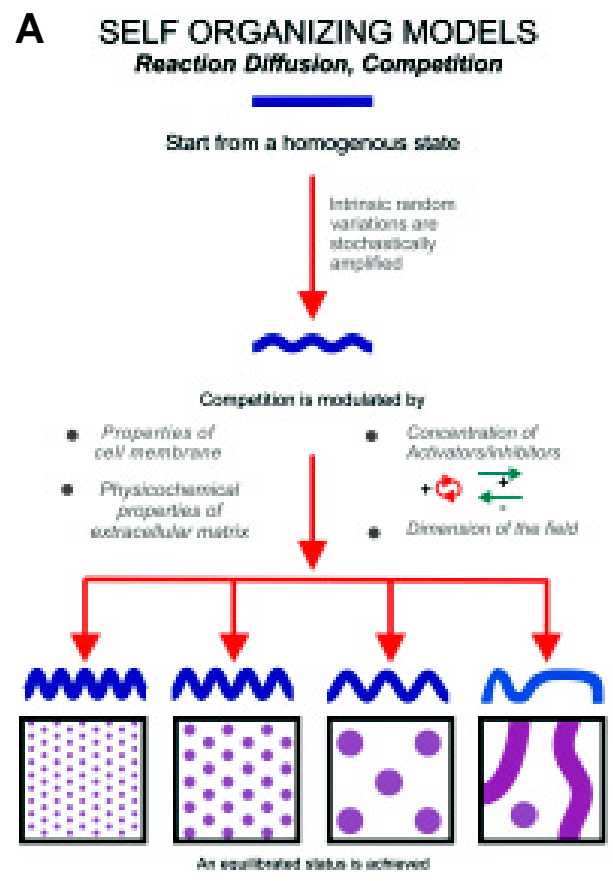

B DIGITAL HORMONE MODEL

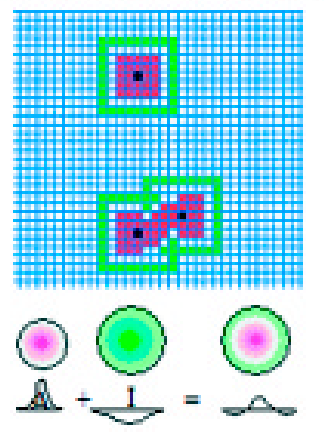

Fig. 6. Diagram of self-organizing models for pattern formation. (A) Homogenously distributed cells through random interactions form unstable aggregates. This forms random variations which are amplified above a threshold at which the patterns become set. Distinctpatterns are formed by competition between intrinsic factors (properties of the membranes and extracellular matrix), concentrations of activators and inhibitors and the size of the primordial field. (B) Digital hormone model. Cells (black dots) can move within the grid. They secrete activators (red) and inhibitors (green) that influence neighboring cells which fall within their sphere of influence. Activators and inhibitors cancel each other out in the space between the red and green regions. In the lower portion of the figure, two cells are interacting through their hormones. If the activator/inhibitor ratio is high (lower left figure) feather formation is highly favored. If the activator) inhibitor ratio is low (lower middle figure) feather formation is suppressed. If the activator/inhibitor ratio is balanced (lower right figure) feather buds and interbuds will form. 
gous results can be derived from arbitrary dimensions. The concentration of each hormone is a function of position and time. Cells will then respond to the signals. The effects of each signal (increase adhesion, decrease adhesion) can be assigned.

4) How the model works. From the above, the DHM defines the response of a group of competent cells which move dynamically and randomly in a field. These cells interact with each other (manifested as cell adhesion) and extra-cellular signaling hormones whose distributions are controlled by reaction-diffusion. Cells respond to these signals with topological stochastic actions that can only be described in terms of their probability.

To demonstrate the DHM, we define a simple DHMO shown in Fig. 6B. Here cells are shown as black dots and can move in a space of discrete grids. Each cell occupies one grid at a time and can secrete hormones (shown as the gray areas around a cell) to the neighboring grids to influence other cellsí behaviors. For simplicity, we assume for now that all cells synchronize their actions and the grids carry out the reaction and diffusion of hormones. A cell at a grid $(a, b)$ can secrete two types of hormones, the activator $A$ and the inhibitor I (More than two can be assigned). We assume that the hormone $A$ has a positive value and the hormone I has a negative value. For a single isolated cell, the hormone concentration in its neighboring grids looks like three "colored rings" (see the lower-right corner in Fig. 6B). Because of differences in diffusion rates, we presume that the activator hormone dominates the inner ring; the inhibitor hormone dominates the outer ring; and the middle ring is neutral where the hormones of $A$ and I have canceled the effects of each other. The reaction between two hormones in a grid is computed by summing up all present "A"s and "I"s in the grid. Cells do not have identities. When two or more cells are near each other, the hormones in the surrounding grids are summed up to compute the hormone strengths. In the upper part of Fig. $6 \mathrm{~B}$, we have illustrated the combined hormones around a single cell and around two nearby cells. Since the grids are discrete, the rings around the cells are shown as squares instead of circles.

DHM can be used to investigate how hormones affect selforganization and whether they can enable locally interacting cells to form globally interesting patterns. They can be applied to in vivo situations such as feather reconstitution here, and we can study the molecular identity of each component. On the engineering side, they can also be applied to study the behaviors of swarming robots in which particular robot configurations can self-form.

\section{Simulations}

Here we would like to test whether the DHM can indeed simulate feather pattern formation in silico. We also can change the characteristics of these parameters, and observe and analyze the effects on global pattern formation. Our questions are listed as follows:

$\checkmark$ Will the DHM enable cells to self-organize into patterns at all?

$\checkmark$ Will the size of final cell clusters be invariant to the cell population density?

$\checkmark$ Assuming that the hormone diffusion profiles are fixed, will the results match the observations made in the feather reconstitution experiments?

$\checkmark$ How do the hormone diffusion profiles affect the size and shape of the final cell clusters as shown in the feather reconstitution experiments? $\checkmark$ Will an arbitrary profile enable self-organization and pattern formation?

To answer these questions, we have conducted two experiments. In the first experiment, we use the same hormone diffusion profile and run a set of simulations on a space of $100 \times 100$ grids with different cell population densities ranging from 10\% ( 1000 cells) through $50 \%$ ( 5000 cells). Starting with cells randomly distributed on the grids, each simulation runs up to 1,000 action steps, and records the configuration snapshots at steps of $0,50,500$, and 1,000. As we can see from the results in Fig. 7A, cells in all simulations indeed form clusters with approximately the same size. These results demonstrate that DHM does enable cells to form patterns. Furthermore, the results match the observations made in the biological experiments: the size of the final clusters (feather primordia) does not change with cell population density, but the number of clusters does (Jiang et al., 1999). Lower cell densities result in fewer final clusters, while higher densities form more clusters. They are of similar size (Fig. 4 E,G).

In the second set of experiments, we started with the same cell population density, but varied the hormone diffusion profiles by changing the parameters for Equation 4 and 5 (please see Appendix). We wanted to observe the effects of different hormone profiles on the results of pattern formation. As we can see in Fig. 7B, when a balanced profile of activator and inhibitor is given (see the second row), the cells will form final patterns as in the first set of experiments. As the ratio of activator over inhibitor increases, the size of final clusters also increases. These results are an exact match with the findings in the reported biological experiments (Jiang et al., 1999; Fig. 4 F,G). When the ratio of $A / I$ becomes so high that there are only activators and no inhibitors, then cells will form larger and larger clusters, and eventually become a single connected cluster. On the other hand, when the ratio is so low that there is only inhibitor and no activator, then the cells will never form any patterns, regardless of how long the simulation runs. Some of the predictions are yet to be seen in biological experiments, but they are consistent with the principles of hormone-regulated self-organization and thus qualified as meaningful predictions of cell self-organization by hormones.

In addition to changing the ratio of activator and inhibitor hormones, we can also change the shape of the field to accommodate different body surface regions (e.g., spinal tract, femoral tract, and remige feather tracts have different shapes) and evaluate their effects on the final patterns. For example, when we make the field into the shape of a plus, with two narrow lengths, the cells formed striped patterns as shown in Fig. 7C. This demonstrates that when cell's hormone diffusion patterns are anisotropic, we can predict that the global patterns will be anisotropic as well. This provides a hint that local action profiles can predict global network performance in a large scale.

The experimental results presented here not only demonstrate that the DHM is indeed an effective tool for simulating and analyzing self-organization and self-repairing phenomena, but that it is also capable of predicting global behaviors based on local hormone interaction profiles. The results suggest that hormones can play a critical role in regulating cell's behaviors because cells in the simulation can be viewed as autonomous and global patterns can form based on stochastic local actions and information exchanges. This provides a departure point for the development and testing of 
new hypotheses, theories, and experiments into selforganization. Since the model is mathematically adjustable, it is effective and efficient for researchers to design new experiments and verify new hypotheses in cell development.

\section{Further patterning}

\section{Intra-bud patterning}

We have discussed the initiation of feather buds from a flat piece of skin in the section on Micropatterning. Many studies have focused on the molecular signals involved in the initiation, proliferation and morphogenesis of feather primordia. However, the fundamental principles underlying the movement of epithelial and mesenchymal cells have not been clearly elucidated. How can they form a placode in a particular location? How are they guided to do so? Are these events independent or coupled with proliferation and differentiation? Are these cells recruited from the general vicinity of the forming feather primordia? How are the boundaries of recruitment zones between neighboring feather primordia established?

Some studies in frog and fish revealed a process called "convergent extension", in which a tissue narrows along one axis and lengthens in a perpendicular axis (reviewed in Wallingford et al., 2002). The process can be observed in different cell behaviors; cell migration, radial intercalation, or cell rearrangement and may play an important role in early feather bud formation. During epithelial placode formation, the epithelium is probably rearranged in a process resembling convergent extension. The feather forms as an elongated bud with epithelium surrounding the mesenchymal cells in a cone-like structure. We have evidence that this formation is interrupted when several Wnts, Noggin, Sprouty, and Dkk are overexpressed.

What are the molecular mechanisms that may govern this process? Non-canonical Wnt pathway members may be directly involved. Overexpression studies showed that Wnt4 and Wnt5a disrupt convergent extension (Moon et al., 1993; Ungar et al., 1995). Many Wnt pathway components were also shown to disrupt the process, including Dishevelled and frizzled (Sokol, 1996; Shi et al., 1998; Medina et al., 2000). In addition, studies in Drosophila showed that convergent extension was regulated by a different set of transducers, including Strabismus (Stbm), Prickle, and JNK (Darken et al., 2002). Other molecules acting upon cell migration or intercalation may also promote convergent extension in developing systems.

Therefore, to intensively study the contribution of convergent extension to feather morphogenesis, it must be approached from several different angles. Several molecular pathways thought to be involved (described above) should be perturbed to provide more insight into this process. Changes in the cytoskeleton associated with cell rearrangements should be visualized. Alterations of the direction or rate of cell motility can be traced using time-lapse microscopy.

When initially formed, the short buds are radially symmetric and proliferation takes place in the distal bud (Fig. 8A). The next
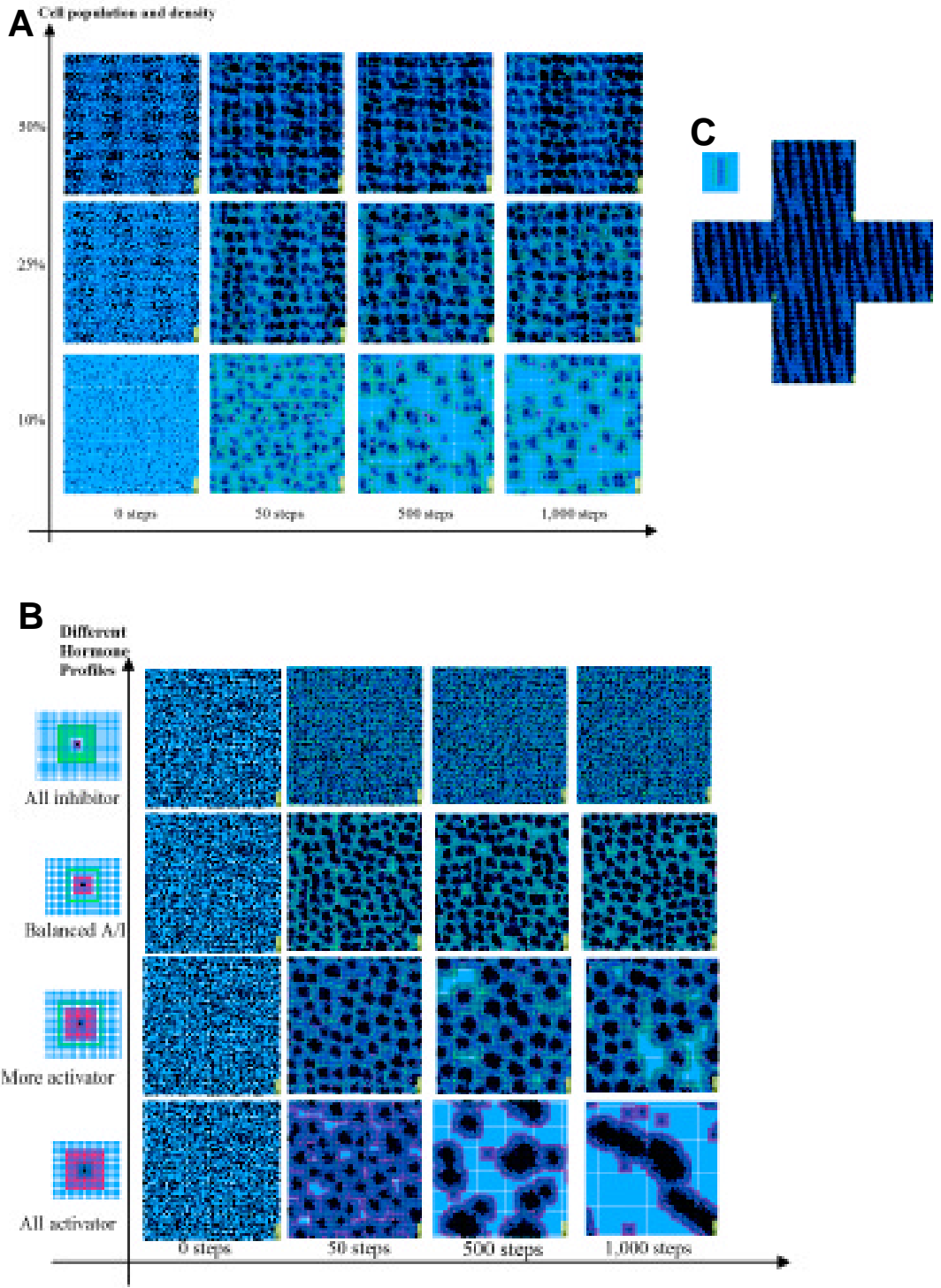

Fig. 7. Simulation of feather patterning by the Digital Hormone Model. (A) Simulations of pattern formation with increasing mesenchymal cell densities $110 \%$, $25 \%, 50 \%$ of grids filled) in a fixed field size indicate that higher cell density favors more aggregates of similar size. The process was captured at step 0, 50, 500 and 1000 to see the dynamic flux of the cell movements. (B) The presence of hormone activators and inhibitors upon pattern formation. Starting with a uniformly dispersed cell population, inhibitors blocked the formation of aggregates. Activators led to the formation of aggregates. As the ratio of activator to inhibitor increased, the size of the cell aggregates increased. The dynamic cell sorting was captured at step 0, 50, 500 and 1000. (C) To test the influence of field shape on pattern formation we started with a field shaped like a plus sign. This caused the virtual cells to form stripes.

level of morphogenesis occurs within the primordia where proliferation generates new cell mass (Desbiens et al., 1992) for subsequent molding and morphogenesis. They then acquire anterior-posterior asymmetry $(\mathrm{A}-\mathrm{P})$. This AP asymmetry interaction information resides in the epithelium at E7 as determined from epithelial - mesenchymal recombination studies (Novel, 1973; Chuong et al., 1996). However, the information is transferred later to the mesenchyme at E8 and it is possible to produce branched feather buds by recombining $E$ and $M$ in frame-shifted 

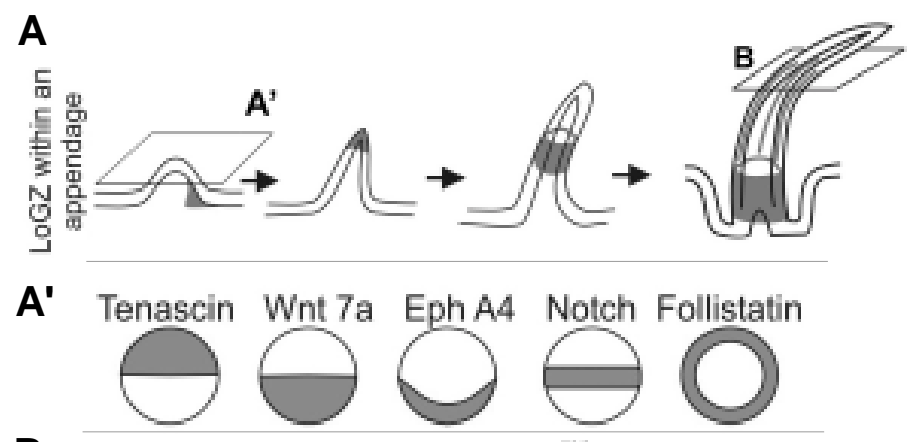

B

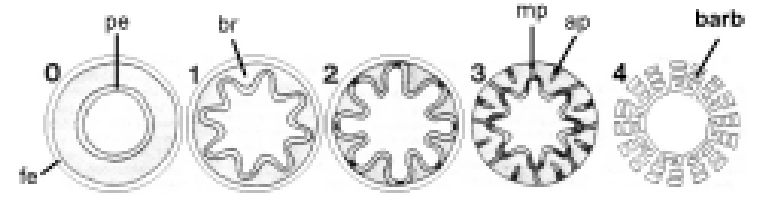

C

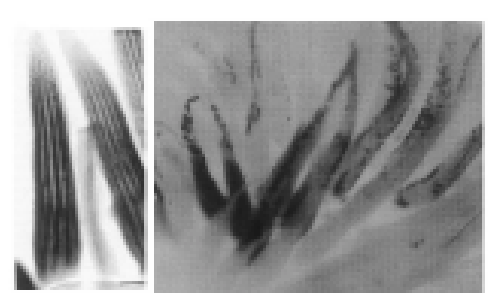

Fig. 8. Further patterning of feather buds and feather filaments. Several factors influence the final shape of each feather. (A) As feathers elongate, a proximal-distal axis starts to develop and molecular differences are seen along this axis. Localized growth zones (LoGZ) are located at the tip of the feather during early development, but become localized near the feather base later. (A') Tangential section of early buds show that the homogenous feather buds become heterogeneous following the development of the anterior -posterior axis. Examples shown include tenascin (Jiang and Chuong, 1992); Wnt 7a (Widelitz et al., 1997); Eph A4 (Patel et al., 1999), Notch (Chen et al., 1997) and Follistatin (Patel et al., 1999). (B) Cross sections of different levels of feather filament are shown schematically which also represent different developmental stages (distal is more mature). Stage 0: initiation of the stratified epithelial cylinder; the basal layer is beginning to form. Stage 1: barb ridge formation initates, the basal layer is well formed. Stage 2: barbule plates and marginal plates begin to form. Stage 3: axial plates are forming and barbule plates are well formed. Stage 4: keratinization is complete; barbs have separated. The numbers and sizes of each structure depicted are schematic and do not reflect the actual values (from Chuong and Edelman, 1985b). (C) Wholemount view of the elongated feather buds. The barb ridges alternate with the marginal plate which is highlighted by staining with Shh. Cell lineage was traced by injecting replication-defective spleen necrosis virus directing the expression of $\beta$-galactosidase at $E 10$ and analyzing expression at E18. The results indicate that it is not one clone - one marginal or barb plate. Instead each individual barb is polyclonal, containing some $\beta$-galactosidase positive and some $\beta$-galactosidase negative cells. ap, axial plate; br, barb ridge; fe, feather epithelium; mp, marginal plate; pe, pulp epithelium.

positions (Chen et al., 1997). The molecular expression pattern also starts to become heterogeneous, reflecting these changes. Fig. 8A' shows some examples with anterior or posterior localization of different molecules in the epithelium or mesenchyme. This is followed by the formation of proximal-distal asymmetries. There is more proliferation in the posterior bud (Fig. 8A; Desbiens et al., 1992; Chen et al., 1997) and lineage tracing showed that posterior buds contribute more to further development (Chuong et al., 1998). Some Hox genes and extracellular matrix molecules (collagen I, III, fibronectin) become AP polarized (Chuong et al., 1990; Mauger et al., 1982). However, anterior buds are essential as experiments showed that over-expression of Wnt $7 \mathrm{a}$ at this stage made buds posteriorized, and these buds could not elongate normally (Widelitz et al., 1999).

The primordia soon develop an AP (anterior - posterior) axis (Fig. 8A') and later a PD (proximal-distal) axis (Fig. 8A). This is evident by the molecular expression pattern. Once molecules are expressed within the feather bud through the restrictive or de novo modes, they generally have a symmetric pattern in a solid circle, central dot, and stripe or ring pattern. Wnt-7a and follistatin are expressed with the solid circle pattern. Sonic hedgehog, BMP-2, Delta-1, R-fringe and Eph-A4 are expressed with the central dot pattern. R-fringe initiates with a ring pattern. The patterns change rapidly. For instance, Wnt-7a soon moves from the solid circle of expression to a ring pattern. Later as the feather buds begin to develop asymmetries, many genes are asymmetrically expressed. Some molecules, such as tenascin-C or BMP-2 are expressed in the anterior region of the feather buds. Others, such as Wnt-7a, L-fringe and Eph-A4 are expressed in the posterior region of the feather buds. Still others, like Notch-1, are expressed as a central stripe which later takes on some posterior expression within the feather buds. At this time, Delta-1 is expressed in a complementary fashion within the boundaries of the Notch-1 expression domain. L-fringe is expressed toward the lateral edge of the feather bud. Hence the feather bud can be divided into a number of different regions with different molecular expression profiles (Fig. 8A').

What are the molecules that control this AP asymmetry? As stated, orientation signaling originates from the epithelia at E6. Differential cell proliferation was examined and more BrdUlabeled cells were found in the posterior region (Desbiens et al., 1992, Chen et al., 1997; Fig. 3B). When the feathers elongated, the posterior feather buds contributed more cells to the future feather bud (Chuong et al., 1998). What could be the molecular basis for this difference? In situ hybridization found enhanced expression of Delta-1 and Serrate- 1 in the posterior feather bud (Chen et. al., 1997) and some FGF receptors were also enriched in the posterior feather buds (Noji et al., 1993). In contrast, the BMP4 and its receptor are localized on the anterior regions. However Delta-1 was in the mesenchyme. Furthermore, HB9, a homeobox gene, was also highly expressed in epidermal basal cells and dermal cells of placodes and feather buds but not in inter-placodes and inter-buds regions (Kosaka et al., 2000). What molecule could be in the epithelium to cause these differences? We found Wnt-7a was in the posterior bud epithelium. Overexpression of Wnt-7a indeed caused feather buds to stop elongating and to become plateau-shaped appendages (Widelitz et al., 1999). Cell proliferation was actually increased, but the whole appendage showed characteristics of posterior feather buds and lost AP asymmetry, such as occurred with over-expression of Delta-1 (Viallet et al., 1998). As a result, no P-D axis formed.

Previously, we showed that activators for protein kinase A, such as cyclic-AMP, also arrested feather bud growth. But these arrested buds were morphologically different from those overexpressing Wnt-7a. In this case, the feather buds were small and round, and deficient in cell proliferation. Further analysis showed that these abnormal buds expressed characteristics of anterior feather buds, such as the loss of sonic hedgehog expression (Noveen et al., 1995b; 1996). Thus, the coexistence and interaction of juxtaposed anterior and posterior bud domains appear to 
be important for the generation of a new growth zone at their interface that will drive the growth of the $P$ - D axis of feathers buds. This is reminiscent of the situation in Drosophila and chicken limb development (LeCuit and Cohen, 1997; Kengaku et al., 1998).

The continued elongation of feather buds depends on the generation of a proliferation center initiating in a distal region between the anterior and posterior feather bud domains. As they continue to proliferate, they become localized at the distal end of the feather bud, to a region enriched with $\mathrm{SHH}$, NCAM, etc. The proximal-distal axis is generated when focal cell proliferation is formed in the distal bud growth zone. However, as feather primordia start to invaginate to form follicles, the proliferating cells come down to the collar epithelia, adjacent to the dermal papilla. At this time point, Wnt 14 and sfrp2 are coincidently expressed in the proliferation regions (Chodankar et al., 2003). This is in contrast to limb appendage development in which the growth zone, composed of the apical ectodermal ridge and the progress zone, remains in the distal end and eventually disappears, losing the ability for further elongation or regeneration. Skin appendages, including

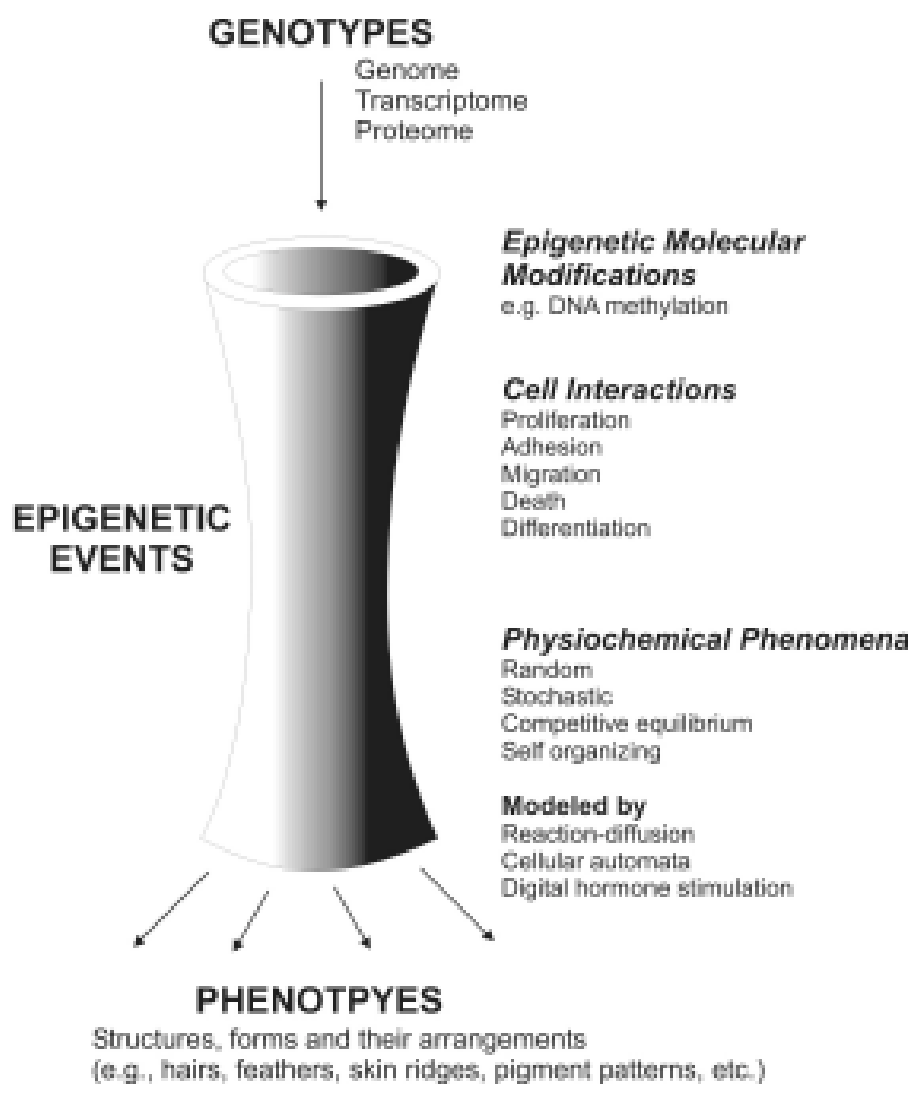

Fig. 9. Schematic diagram depicting the genotype, the epigenetic events at different organization levels and the resultant phenotypes. While genetics (genome, transcriptome, proteome) provides the basic molecular composition, probability events and variations occur at the cell interaction level. Cell fate decisions are based on basic cellular interactions (proliferation, adhesion, migration, death and differentiation). They are ruled by physiochemical phenomena (stochastic randomness, competitive equilibrium, self-organization). These factors have been modeled by reaction diffusion, cellular automata and digital hormones. feathers and hairs form follicles and keep the growth zone cells at the protected proximal end of the follicle. The continued interaction between the dermal papilla and collar epithelia produce sustained cell proliferation which drives proximal-distal elongation of the feather bud, and also allows future feather molting and cycling. During feather bud maturation, the initial radial symmetry placodes begin to specify anterior-posterior $(A-P)$ asymmetry and then turn to growth in the proximal- distal (P-D) direction. That involves many cell behaviors such as proliferation, differentiation, and migration, which are regulated by the above genes and adhesion molecules. They control each side of the feather bud and build up the three dimensions of feather growth.

\section{Periodic patterning of feather filaments: formation of branches}

Feathers initially form as a cylinder (Fig. 8B, stage 0). At this stage the pulp epithelium (pe) surrounds the pulp and the feather epithelium ( $\mathrm{fe}$ ) surrounds the feather follicle. The feather then begins to invaginate to form the barb ridges (br) at stage 1 . The size, number and spacing of barb ridges are specific in different feathers. Their molecular control remains much unknown other than that BMP favors fusion of barb ridges and noggin favors further branching of barb ridges (Yu et al., 2002). In radially symmetric downy feathers, all barb ridges form at about the same time. In bilaterally symmetric feathers, they take a sequential appearance order. New barbs are generated in the barb generative zone (posterior) and spread toward the rachis (anterior), the side that is more differentiated. This periodic patterning event takes place along the circular perimeter of the cylindrical feather filament epidermis. When the feather filaments elongate, new cells are added to the proximal end. Therefore an additional dimension is the time. The pulp epithelium extends out to connect with the feather epithelium at stage 2. The axial plate (ap), marginal plate ( $\mathrm{mp}$ ) and barb plate epithelium then form. The barb plate lives to become the feather barbs. The barbs can be visualized by staining with Shh (Fig. $8 \mathrm{C}$ ). The axial plate later dies to release the proximal and distal sides of each feather barb. The marginal plate epithelium also dies to separate the barbs (Chang et al., 2004b). The pulp dies which enables the feathers to unfurl and assume their distinct shapes. We examined how cell lineage contributes to barb formation by labeling the somites with LacZ at E10. By E18, the cells had moved out into the skin (Fig. 2E) and become incorporated into the growing feather follicles (Fig. 8C). To our surprise the cell lineage did not correlate with the formation of the barb ridges. These cells were organized later into each of the feather structures. Molecular and cellular aspects of barb formation are described in more detail in Yu et al., 2004.

\section{Conclusion}

Through the experimental analysis of feather morphogenesis and the literature review of other integuments, we can conclude that there is both genetic and epigenetic control of integument pattern formation. The genetic control provides transcription and translational control of molecules. Specific sets of cell surface molecules and intra-cellular signaling are produced for particular cell types. The molecular information endows cells and their micro-environment with particular properties. Based on these properties, cells interact in accordance to physical-chemical rules, and there are competition, equilibrium, randomness, and sto- 
chastic events, at this cellular level. Epigenetic events appear to play important roles at the cellular level. The integument pattern we observe is the sum of these cell behaviors.

Genetic control provides combinational molecular information that defines the properties of the cells but not the final pattern. Epigenetic control governs interactions among cells and their environment based on physical-chemical rules. Integument pattern is the sum of these two components of control and that is why they are usually similar but non-identical (Fig. 9).

\section{Acknowledgement}

We thank the support from NIH (CMC, AR42177, 47364, 47364: RW, CA83716), NSF (CMC, IBN9808874), and Korea Research Foundation Grant (HSJ, KRF-2000-015-DP0363). We thank Dr. Danielle Dhouailly for helpful comments, Dr. Hans Meinhardt for valuable criticism, and Mr. Michael Hughes for the discussion on dolphin skin.

\section{Appendix}

\section{Digital Hormone Model}

We developed a Digital Hormone Model (DHM) for simulating the self-organization phenomena observed in feather patterning. Another motivation is that this model can also be used to develop robots that can form different configurations (Shen et al., 2004; Shen et al., 2002).

Mathematically speaking, the Digital Hormone Model consists of three components: 1 ) a self-reconfigurable network (or set) of cells, 2) a probabilistic function for individual cell behavior, and 3) a set of equations for hormone reaction, diffusion, and dissipation.

\section{1) A self-reconfigurable network}

This indicates a network (or set) of $\mathrm{N}$ autonomous cells that can form different configurations repetitively. Each cell has a set of connectors (adhesion molecules) through which the cell can dynamically connect to other cells to form edges for communication or physical (mechanical or chemical) coupling. The connectors are valuable and finite resources for cells. Because connectors can be joined and disjoined, they make the edges in a network dynamic, and the reconfiguration of network possible. Let $\mathrm{Nt}$ and Et denote all the cells and edges in a self-reconfigurable network at time $t$, then we denote

$$
\text { (Equation 1) } \quad D N S R_{t} \equiv\left(N_{t}, E_{t}\right)
$$

as the self-reconfigurable network at time t. Note that both $\mathrm{Nt}$ and $\mathrm{Et}$ can change dynamically because cells can autonomously join, leave, or be damaged. Edges can be formed and disconnected by the connectors of the cells. Different from classical simulation models, cells do not have unique identities. The number of cells and edges in the network is not known, and there is no global broadcast. A cell can only communicate with its current neighbors through its current edges. Through local communication, cells can either generate hormones or propagate hormones. By default, a generated hormone will be sent to all the current edges of its generator, and a received hormone will be propagated to all the current edges except the one through which the hormone is received.

\section{2) Specification of individual cell behavior}

This is similar to the concept of "receptors". A cell in the network can select its actions, $B$, based on a probability function, $P$, that is conditioned on four local factors: the connector information, C; the sensor information, $\mathrm{S}$; the values of local variables, $\mathrm{V}$; and the received hormones, $\mathrm{H}$ :

$$
\text { (Equation 2) } \quad P(B \mid C, S, V, H)
$$

The actions, B, of a cell include the actions internal to a cell, as well as actions that change connectors and generate or propagate hormones. Different from most existing probabilistic models, the $P$ function here considers not only sensor and state information $S$ and $\mathrm{V}$, but also topological information, $\mathrm{C}$, and communication information, $\mathrm{H}$. These allow the Digital Hormone Model to support dynamic reconfigurations and self-organization in network structures. The function $P$ is local and homogenous for all cells, but can greatly influence the global behaviors of the network and predict and analyze the global network performance in the large. For example, in the simulation of feather formation, the characteristics of $P$ can influence whether or not any global patterns can be formed. Biologically speaking, we believe that the function $P$ partially simulates the hormone receptors and the control mechanisms found in biological cells. The P function is programmed by the system designers initially, but can be dynamically changed by the cells themselves through learning techniques.

\section{3) Specification for hormone reaction, diffusion and dissipa- tion}

Following Turing (1952) and Giere and Meinhardt (1972), we assume in the mathematical description that hormone reaction and diffusion occur through a two-dimensional medium, although analogous results can be derived for arbitrary dimensions and some higher dimensions are indeed used in applications of selfreconfigurable cells. The concentration of each hormone is a function of position and of time. We denote the concentration function for a particular hormone by $C(x, y)$, where $x$ and $y$ are $2 D$ space dimensions. The reaction-diffusion-dissipation equation governing the hormone is then given by:

$$
\text { (Equation 3) } \frac{\partial C}{\partial t}=\left(a_{1} \frac{\partial^{2} C}{\partial x^{2}}+a_{2} \frac{\partial^{2} C}{\partial y^{2}}\right)+R-b C
$$

The first term on the right is for diffusion, and a1 and a2 are constants that represent the rate of diffusion in $\mathrm{x}$ and $\mathrm{y}$ directions respectively. The function $R$ is the reaction function governing $\mathrm{C}$, which depends on all the other concentrations of hormones. The constant $b$ is the rate for dissipation. The equation (3) is usually considered to be a part of an environmental function $G$ responsible for the implementation of the dynamics of communication or other effects of actions. For example, if two cells send out signals at the same time, then $G$ will be responsible for simulating the interference or synergistic effects between the two signals. Although the $\mathrm{G}$ function is in principle a part of the environment, it can be simulated by the actions of the cells as described later. 


\section{4) Integration}

As we can see from the above definitions, the Digital Hormone Model is an integration of dynamic network (Equation 1), topological stochastic action selection (Equation 2), and distributed control by hormone reaction-diffusion (Equation 3). This integration provides a very powerful coordination mechanism for dynamic networks of dissociated cells. The execution of DHM is very simple. All cells in the network asynchronously execute the basic control loop as follows: 1. Select actions by $\mathrm{P}(\mathrm{B} \mid \mathrm{C}, \mathrm{S}, \mathrm{V}, \mathrm{H})$; (2) Execute the selected actions in $\mathrm{B}$; (3) Perform hormone generations and propagations; (4) Simulate hormones diffusion, reaction, and dissipation; (5) Go to Step (1).

To demonstrate the DHM, we define a simple DHMO shown in Fig. 7A. In this simple model, cells are shown as black dots and can move in a torus space of discrete grids. Each cell occupies one grid at a time and can secrete hormones (shown as the gray areas around a cell) to the neighboring grids to influence other cellsí behaviors. For simplicity, we assume for now that all cells synchronize their actions and the grids carry out the reaction and diffusion of hormones. A cell at a grid $(a, b)$ can secrete two types of hormones, the actiivator $A$ and the inhibitor $I$. The diffusion of $A$ and $\mathrm{I}$ at a surrounding grid $(\mathrm{x}, \mathrm{y})$ are given by the standard distribution functions:

$$
\begin{aligned}
& \text { (Equation 4) } \quad C_{A}(x, y)=\frac{a_{A}}{2 \pi \sigma^{2}} e^{\frac{(x-a)^{2}+(y-b)^{2}}{2 \sigma^{2}}}+R \\
& \text { (Equation 5) } \quad C_{I}(x, y)=-\frac{a_{I}}{2 \pi \rho^{2}} e^{\frac{(x-a)^{2}+(y-b)^{2}}{2 \rho^{2}}}+R
\end{aligned}
$$

where $a_{A}, a_{p} \sigma$, and $\rho$ are constants, and $\sigma<\rho$ in order to satisfy the Turing stability condition that the diffusion rate of the inhibitor must be greater than that of the activator. Note that because $\sigma<\rho, A$ has a sharper and narrower distribution than I, and these characteristics are similar to those observed in the biological experiments. We assume that the hormone $A$ has the positive value and the hormone I has the negative value. For a single isolated cell, the hormone concentration in its neighboring grids looks like three "colored rings" (see the lower-right corner in Fig. 6A). The activator hormone dominates the inner ring; the inhibitor hormone dominates the outer ring; and the middle ring is neutral where the hormones of $A$ and I have canceled each other. The reaction between two hormones in a grid is computed by summing up all present "A"s and "I"s in the grid:

$$
\text { (Equation 6) } \quad R=\sum_{N}\left(C_{A}+C_{I}\right)
$$

When two or more cells are near each other, the hormones in the surrounding grids are summed up to compute the hormone strengths. In the upper part of Figure $6 \mathrm{~B}$, we have illustrated the combined hormones around a single cell and around two nearby cells. Since the grids are discrete, the rings around the cells are shown as squares instead of circles.

When all cells are moving in synchronization, there may be a chance that multiple cells will "collide" in the same grid. The collision of cells is solved in a simple manner. All cells first "virtually" move to the grids they selected. If there are multiple cells in the same grid, then the extra cells will be randomly distributed to those immediate neighboring grids that are empty. This is an environmental function, not a cellular action. But this action will ensure that no grid is hosting more than one cell at any time.

For cell behaviors, DHM is governed by a function $\mathrm{P}_{0}(\mathrm{~B} \mid \mathrm{C}, \mathrm{S}, \mathrm{V}$, H) defined as follows:

$B$ : Each cell has ten actions. $B_{0}$ for secreting the $A$ and $I$ hormones, and $B_{1}, \ldots, B_{9}$ for moving into the nine neighboring grids: north, south, west, east, northeast, northwest, southeast, southwest, and self (the occupying grid);

$\mathrm{C}$ : Each cell has eight connectors in this simple model, one for each neighboring grid;

S: Each cell has nine hormone sensors, one for each of the neighboring grids;

V: Cells have no local variables in this model;

$\mathrm{H}$ : The nine hormone values sensed by the sensors.

\section{References}

ARTAVANIS-TSAKONAS, S., MATSUNO, K. and FORTINI, M.E. (1995). Notch signling. Science 268: 225-268.

ASAI, R., TAGUCHI, E., KUME, Y., SAITO, M. and KONDO, S. (1999). Zebrafish leopard gene as a component of the putative reaction-diffusion system. Mech Dev. 89: 87-92.

ATIT, R., CONLON, R.A. and NISWANDER, L. EGF signaling patterns the feather array by promoting the interbud fate. Dev Cell. 2003 4: 231-40.

BEREITER-HAHN, J., MATOLTSY, A.G., RICHARDS, K.S. (eds.) 1986. Biology of the Integument. 2. Vertebrates. Berlin: Springer Verlag.

BOTCHKAREV, V.A., BOTCHKAREVA, N.V., SHAROV, A.A., FUNA, K., HUBER O. and GILCHREST, B.A. (2002). Modulation of BMP signaling by noggin is required for induction of the secondary (nontylotrich) hair follicles. J. Invest. Dermatol. 118: 3-10.

CHANG, C.H., JIANG, T.X., LIN, C.M., BURRUS, L.W., CHUONG, C.M. and WIDELITZ, R.W. (2004a) Distinct Wnt members regulate the hierarchical morphogenesis of skin regions (spinal tract) and individual feathers. Mech. Develop. In press.

CHANG, C.H., YU, M.K., WU, P., JIANG, T.X., YU, H.S., WIDELITZ, R.B. AND CHUONG, C.M., (2004b). Sculpting skin appendages out of epidermal layers via temporally and spatially regulated apoptotic Events. J. Investig. Dermatol. 121: $157-171$.

CHEN, J.C.-W., JUNG, H.-S., JIANG T.-X. and CHUONG, C.-M. (1997). Asymmetric expression of Notch, Serrate and Delta is associated with the anterior posterior axis of feather buds. Dev. Biol. 188: 181-187.

CHEN, C.W. and CHUONG, C.M. (1999). Avian integument provides multiple possibilities to analyse different phases of skin appendage morphogenesis. $J$ Investig Dermatol Symp Proc. 4: 333-337.

CHEN, C.-W. J., and CHUONG, C.-M. (2000). Dynamic expression of /unatic fringe during feather morphogenesis: a switch from medial-lateral to anterior-posterior asymmetry. Mech. Dev.: 91: 351-354.

CHODANKAR, R., CHANG, C.-H., YUE, Z., SUKSAWEANG, S., BURRUS, L., CHUONG, C.-M., and WIDELITZ, R.B. (2003). Shift of Localized Growth Zones (LoGZ) Contributes to the MorphogEnesis of Skin Appendages: Association with Wnt/ $\beta$-catenin activities. J Invest Dermato/120: 19-26.

CHUONG, C.-M. (1998). Morphogenesis of epithelial appendages: Variations on top of a common theme and implications in regeneration. In Molecular basis of epithelial appendage morphogenesis. (C.M. Chuong, ed.). R.G. Landes, Georgetown, Tx. pp 3-13.

CHUONG, C.M. and EDELMAN, G.M. (1985a). Expression of cell-adhesion molecules in embryonic induction. I. Morphogenesis of nestling feathers. J Cell Biol. 101: 1009-1026. 
CHUONG, C.M. and EDELMAN, G.M. (1985b). Expression of cell adhesion molecules in embryonic induction. II. Morphogenesis of adult feathers. J Cell Biol101: 1027-1043.

CHUONG, C.-M., OLIVER, G., TING, S. JEGALIAN, B., CHEN, H.M. and DE ROBERTIS, E.M. 1990. Gradient of homeoproteins in developing feather buds. Development 110: 1021-1030.

CHUONG, C.M., TING, S.A., WIDELITZ, R.B. and LEE, Y.S. (1992). Mechanism of skin morphogenesis. II. Retinoic acid modulates axis orientation and phenotypes of skin appendages. Development. 115: 839-852.

CHUONG, C.-M., TING-BERRETH, S., WIDELITZ, R.B., and JIANG, T.-X. (1996). Early events during the regeneration of skin appendages: order of molecular reappearance following epithelial-mesenchymal recombination with rotation. $J$. Invest. Dermatol. 107: 639-646.

CHUONG, C.-M., JUNG, H.-S., NODEN, D. and WIDELITZ, R.B. (1998). Lineage and pluripotentiality of epithelial precursor cells in developing chicken skin. Biochem. Cell Biol. 76: 1069-1077.

COLLIER, R.C., Monk, N.A.M., MAINI, P.K. and LEWIS, J.H. (1996). Pattern formation by lateral inhibition with feedback: A mathematical model of DeltaNotch intercellular signalling. J. Theor. Biol. 183: 429-446.

COOKE, J. and ZEEMAN, E.C. (1976). A clock and wavefront model for control of the number of repeated structures during animal morphogenesis. $J$ Theor Biol. 58: $455-476$.

CROWE, R., HENRIQUE, D., ISH-HOROWICZ, D. and NISWANDER, L. (1998). A new role for Notch and Delta in cell fate decisions: patterning the feather array. Development 125: 767-775.

CRUYWAGEN, G.C., MAINI, P.K. and MURRAY, J.D. (1992). Sequential pattern formation in a model for skin morphogenesis. IMA JMath App/Med Biol. 9: 227248.

DARKEN, R.S., SCOLA, A.M., RAKEMAN, A.S., DAS, G., MLODZIK, M. and WILSON, P.A. (2002). The planar polarity gene strabismus regulates convergent extension movements in Xenopus. EMBO J. 21: 976-985.

DAVIDSON, D. (1983). The mechanism of feather pattern development in the chick. 1. The time of determination of feather position. J Embryol Exp Morphol. 74: 245259.

DESBIENS, X., TURQUE, N., and VANDENBUNDER, B. (1992). Hydrocortisone perturbs the cell proliferation pattern during feather morphogenesis: evidence for disturbance of cephalocaudal orientation. Int. J. Dev. Biol. 36: 373-380.

DHOUAILLY, D. (1975). Formation of cutaneous appendages in dermo-epidermal interactions between reptiles, birds and mammals. Roux Arch Dev Biol. 177: 323-340.

DHOUAILLY, D. (1977). Dermo-epidermal interactions during morphogenesis of cutaneous appendages in amniotes. Front. Matrix Biol. 4: 86-121.

EDE, D.A. (1972). Cell behaviour and embryonic development. Int J Neurosci. 3: 165-174.

GIERER, A. and MEINHARDT, H. (1972). A theory of biological pattern formation. Kybernetik. 12: 30-39.

HAMRICK, M.W. (2003). Evolution and development of mammalian limb integumentary structures. J Exp Zool Part B Mol Dev Evol. 298: 152-163.

HAPPLE, R. (1985). Lyonization and the line of Blaschko Human. Genetics70: 200206

HAPPLE R. (1993). An early drawing of Blaschko's lines. Br J Dermatol. 128: 464. HARDY, M.H. (1992). The secret life of the hair follicle. Trends Genet. 8: 55-61.

HARRIS, A.K., STOPAK, D. and WARNER, P. (1984). Generation of spatially periodic patterns by a mechanical instability: a mechanical alternative to the Turing model. J Embryol Exp Morphol. 80: 1-20.

HEADON, D.J., EMMAL, S.A., FERGUSON, B.M., TUCKER, A.S., JUSTICE, M.J., SHARPE, P.T., ZONANA, J. and OVERBEEK, P.A. (2001). Gene defect in ectodermal dysplasia implicates a death domain adapter in development. Nature. 414: 913-916.

HELD, L.I. (1992). Models for Embryonic Periodicity. New York, Karger.

HOGAN, B.L. (1999). Morphogenesis. Cel/96: 225-233.

JAIN, A.K., PRABHAKAR, S. and PANKANTI, S. (2002). On the similarity of identical twin fingerprints. Pattern Recognition 35: 2653-2663.

JIANG, T.X. and CHUONG, C.M. (1992). Mechanism of skin morphogenesis. I.
Analyses with antibodies to adhesion molecules tenascin, N-CAM, and integrin. Dev. Biol. 150: 82-98

JIANG, T.-X., JUNG, H.-S., WIDELITZ, R.B. and CHUONG, C.-M. (1999). Self organization is the initial event in periodic feather patterning: Roles of signaling molecules and adhesion molecules. Development. 126: 4997-5009.

JUNG, H.-S. and CHUONG, C.-M. (1998). Periodic pattern formation of the feathers. In Molecular basis of epithelial appendage morphogenesis. (C.M. Chuong, ed.). R.G. Landes, Georgetown, Tx. pp 359-369.

JUNG, H.-S., FRANCIS-WEST, P.H., WIDELITZ, R.B., JIANG, T.-X., TING-BERRETH S., TICKLE, C., WOLPERT, L. and CHUONG, C.-M. (1998). Local inhibitory action of BMPs and their relationships with activators in feather formation: implications for periodic patterning. Dev. Biol. 196: 11-23.

JUNG, H.S., WOLPERT, L. and DAVIDSON, D. (1999). The formation of the feather pattern in chick skin after a proportion of cells have been killed by $\mathrm{X}$-irradiation. Int J Dev Biol. 43: 117-123.

KENGAKU, M., CAPDEVILA, J., RODRIGUEZ-ESTEBAN, C., DE LA PENA, J., JOHNSON, R.L., IZPISUA-BELMONTE, J.C. and TABIN, C.J. (1998). Distinct WNT pathways regulating AER formation and dorsaoventral polarity in the chick limb bud. Science 280: 1274-1277.

KONDO, S. and ASAI, R., (1995). A reaction-diffusion wave on the marine angelfish Pomacanthus. Nature 376: 765-768.

KOSAKA, Y., AKIMOTO, Y., OBINATA, A. and HIRANO, H. (2000). Localization of HB9 homeobox gene mRNA and protein during the early stages of chick feather development. Biochem. Biophys. Res. Commun. 276: 1112-1117.

LECUIT, T. and COHEN, S.M. (1997). Proximal-distal axis formation in the Drosophila leg. Nature. 388: 139-145.

LINSENMAYER, T.F. (1972). Control of integumentary patterns in the chick. Dev Biol. 27: $244-271$.

LUCAS, A.M. and STETTENHEIM, P.R. (1972). Avian Anatomy: Integument. Agriculture Handbook 362.

MAUGER, A., DEMARCHEZ, M., HERBAGE, D., GRIMAUD, J.A., DRUGUET, M. HARTMANN, D. and SENGEL, P. (1982). Immunofluorescent localization of collagen types I and III, and of fibronectin during feather morphogenesis in the chick embryo. Dev. Biol. 94: 93-105.

MAYERSON, P.L. and FALLON, J.F. (1985). The spatial pattern and temporal sequence in which feather germs arise in the white Leghorn chick embryo. Dev. Biol. 109: 259-267.

MEDINA, A., REINTSCH, W. and STEINBEISSER, H. (2000). Xenopus frizzled 7 can act in canonical and non-canonical Wnt signaling pathways: implications on early patterning and morphogenesis. Mech Dev. 92: 227-237.

MEINHARDT, H. and GIERER, A. (1974). Applications of a theory of biological pattern formation based on lateral inhibition. J. Cell Sci. 15: 321-346.

MEINHARDT, H. and GIERER, A. (2000). Pattern formation by local self-activation and lateral inhibition. Bioessays 22: 753-60.

MOON, R.T., CHRISTIAN, J.L., CAMPBELL, R.M., MCGREW, L.L., DEMARAIS, A.A., TORRES, M., LAI, C.J., OLSON, D.J. and KELLY, G.M. (1993). Dissecting Wnt signalling pathways and Wnt-sensitive developmental processes through transient misexpression analyses in embryos of Xenopus laevis. Dev Suppl:: 85-94.

MOORE, G.P., JACKSON, N., ISAACS, K. and BROWN, G. (1998). Pattern and morphogenesis in skin. J. Theor. Biol. 191: 87-94.

MURRAY, J.D. OSTER, G.F. and HARRIS, A.K. (1983). A mechanical model for mesenchymal morphogenesis. J. Math. Biol. 17: 125-129.

NAGORCKA, B.N. AND MOONEY, J.R. (1985). The role of a reaction-diffusion system in the initiation of primary hair follicles. Theor. Biol. 114: 243-272.

NOJI, S., KOYAMA, E., MYOKAI, F., NOHNO, T., OHUCHI, H., NISHIKAWA, K. and TANIGUCHI, S. (1993). Differential expression of three chick FGF receptor genes, FGFR1, FGFR2 and FGFR3, in limb and feather development. Prog. Clin. Biol. Res. 383B: $645-654$

NORAMLY, S. and MORGAN, B.A. (1998). BMPs mediate lateral inhibition at successive stages in feather tract development. 1998 Development 125: 3775-3787.

NORAMLY, S., FREEMAN, A. and MORGAN, B.A. (1999). $\beta$-catenin signaling can initiate feather bud development. Development 126: 3509-3521.

NOVEEN, A., JIANG T.X., TING-BERRETH, S.A., and CHUONG, C.-M. (1995a). Homeobox genes Msx-1 and Msx-2 are associated with induction and growth of skin appendages. J. Invest. Dermatol. 104: 711-719. 
NOVEEN, A., JIANG. T.-X. and CHUONG C.-M. (1995b). Protein Kinase A and Protein Kinase C Modulators Have Reciprocal Effects on Mesenchymal Condensation during Skin Appendage Morphogenesis. Dev. Biol. 171: 677-693.

NOVEEN, A., JIANG, T.X. and CHUONG, C.-M. (1996). CAMP, an activator of protein kinase $A$, suppresses the expression of sonic hedgehog. Biochem. Biophys. Res. Commun. 219: 180-185.

NOVEL, G. (1973). Feather pattern stability and reorganization in cultured skin. J. Embryol. Exp. Morphol. 30: 605-633.

OHYAMA, A., SAITO, F., OHUCHI, H. and NOJI, S. (2001). Differential expression of two BMP antagonists, gremlin and Follistatin, during development of the chick feather bud. Mech Dev. 100: 331-333.

OLIVERA-MARTINEZ, I., THELU, J., TEILLET, M.-A., and DHOUAILLY, D. (2001). Dorsal dermis development depends on a signal from the dorsal neural tube, which can be substituted by Wnt-1. Mech. Dev. 100: 233-244.

OLIVERA-MARTINEZ, I., MISSIER, S., FRABOULET, S., THELU, J. and DHOUAILLY, D. (2002). Differential regulation of the chick dorsal thoracic dermal progenitors from the medial dermomyotome. Development 129: 47634772

OSTER, G.F., MURRAY, J.D. and HARRIS, A.K. (1983). Mechanical aspects of mesenchymal morphogenesis. J. Embryol. Exp. Morphol. 78: 83-125.

PARICHY, D.M. and JOHNSON, S.L. (2001). Zebrafish hybrids suggest genetic mechanisms for pigment pattern diversification in Danio. Dev. Genes Evol. 211 : 319-328.

PATEL, K., MAKARENKOVA, H. and JUNG, H.-S. (1999). The role of long range, local and direct signalling molecules during chick feather bud development involving the BMP's, follistatin and the Eph receptor tyrosine kinase Eph-A4. Mech. Dev. 86: 51-62.

PAUS, R., MULLER-ROVER, S., VANDER VEEN, C., MAURER, M., EICHMULLER, S., LING, G., HOFMANN, U., FOITZIK, K., MECKLENBURG, L. and HANDJISKI B. (1999). A comprehensive guide for the recognition and classification of distinct stages of hair follicle morphogenesis. J. Invest. Dermatol. 113b: 523532.

PISPA, J. and THESLEFF, I. (2003) Mechanisms of ectodermal organogenesis. Dev. Biol. 262: 195-205.

POURQUIE, O. (2003) The segmentation clock: converting embryonic time into spatial pattern. Science. 301:328-330.

PRUM, R.O. and WILLIAMSON, S. (2002). Reaction-diffusion models of withinfeather pigmentation patterning. Proc R Soc Lond B Biol Sci. 269: 781-792.

RIDGWAY, S.H. and CARDER, D.A. (1993). Features of dolphin skin with potential hydrodynamic importance. IEED Engineering in Medicine and Biology. 12: 8388.

SENGEL, P. (1976). Morphogenesis of skin. In Developmental and Cell Biology Series (M. Abercrombie, D.R. Newth, and J.G. Torrey, Eds.), Cambridge Univ. Press, Cambridge.

SENGEL, P. (1978). Feather pattern development. CIBA Found. Symp. 28: 51-70.

SHEN, W.-M., WILL, P., GALSTYAN, A. and CHUONG, C.-M. (2004). Hormoneinspired self-organization and distributed control of robotic swarms. Autonomous Robots 17: 93-105.

SHEN, W.-M., CHUONG, C.-M., and WILL, P. (2002). Simulating Self-Organization for Multi-Robot Systems. International Conference on Intelligent and Robotic Systems, Switzerland.

SHI, D.L., GOISSET, C. and BOUCAUT, J.C. (1998). Expression of Xfz3, a Xenopus frizzled family member, is restricted to the early nervous system. Mech Dev. 70: 35-47.

SIMPSON, P. (2002) Evolution of development in closely related species of flies and worms. Nat Rev Genet. 3:907-917.

SOKOL, S.Y. (1996). Analysis of Dishevelled signalling pathways during Xenopus development. Curr Biol. 6:1456-1467.
SONG, H., WANG, Y and GOETINCK, P.F. (1996). Fibroblast growth factor 2 can replace ectodermal signaling for feather development. Proc. Natl. Acad. Sci. US A. 93: 10246-10249.

STEINBERG, M.S. (1975). Adhesion-guided multicellular assembly: a commentary upon the postulates, real and imagined, of the differential adhesion hypothesis, with special attention to computer simulations of cell sorting. J. Theor. Biol. 55: 431-443.

SULLIVAN, J.A. (1972). Effect of epidermal rotation on orientation of scales in the chick. Dev Biol. 28: 176-182.

SUZUKI, N., HIRATA, M. AND KONDO, S. (2003). Traveling stripes on the skin of a mutant mouse. Proc. Natl. Acad. Sci., USA 100: 9680-9685

TING-BERRETH, S.A. and CHUONG, C.-M. (1996a). Sonic Hedgehog in feather morphogenesis: induction of mesenchymal condensation and association with cell death. Dev. Dyn. 207: 157-170.

TING-BERRETH, S.A. and CHUONG, C.-M. (1996b). Local delivery of TGF $\beta 2$ can substitute for placode epithelium to induce mesenchymal condensation during skin appendage morphogenesis. Dev Biol. 179: 347-359.

TURING, A.M. (1952). The chemical basis of morphogenesis. Phil. Trans. R. Soc. B. 237: 37-72.

UNGAR, A.R., KELLY, G.M. and MOON, R.T. (1995). Wnt4 affects morphogenesis when misexpressed in the zebrafish embryo. Mech Dev. 52: 153-164.

VIALLET, J.P., PRIN, F., OLIVERA-MARTINEZ, I., HIRSINGER, E., POURQUIE, O. and DHOUAILLY, D. (1998). Chick Delta-1 gene expression and the formation of the feather primordia. Mech. Dev. 72: 159-168.

WALLINGFORD, J.B., FRASER, S.E. and HARLAND, R.M. (2002). Convergent extension: the molecular control of polarized cell movement during embryonic development. Dev. Cell. 2: 695-706.

WIDELITZ, R.B., JIANG, T.-X., NOVEEN, A., CHEN, C.-W. and CHUONG, C.-M. (1996). FGF induces new feather buds from developing avian skin. J. Invest. Dermatol. 107: 797-803.

WIDELITZ, R.B., JIANG, T.X., NOVEEN, A., TING-BERRETH, S.A., YIN, E., JUNG H.S. and CHUONG, C.M. (1997). Molecular histology in skin appendage morphogenesis. Microsc Res Tech. 38: 452-465.

WIDELITZ, R.B., JIANG, T.-X., CHEN, C.-W., STOTT, N.S. and CHUONG, C.-M. (1999). Wnt-7a in feather morphogenesis: involvement of anterior-posterior asymmetry and proximal-distal elongation demonstrated with an in vitroreconstitution model. Development 126: 2577-2587.

WIDELITZ, R.B., JIANG, T.-X., LU, J., and CHUONG, C.-M. (2000). $\beta$-catenin in epithelial morphogenesis: Conversion of part of avian foot scales into feather buds with a mutated $\beta$-catenin. Dev. Biol. 219: 98-114

WIDELITZ, R.B., JIANG, T.X., YU, M., SHEN, T., SHEN, J.Y., WU, P., YU, Z. and CHUONG, C.M. (2003). Molecular biology of feather morphogenesis: a testable model for evo-devo research. J Exp Zoolog Part B Mol Dev Evol. 298: 109-122.

WIGGLESWORTH, V.B. (1940). Local and general factors in the development of pattern in Rhodnius Prolixus (hemiptera). J. Exp. Biol. 17: 180-200.

WINFREE, A.T. (1994). Persistent tangled vortex rings in generic excitable media. Nature. 371: 233-236.

WOLFRAM, S. (2002). A new kind of Science. Wolfram Media Inc.

WOLPERT, L. (1971). Positional information and pattern formation. Curr. Top. Dev. Biol. 6: 183-224.

YU, M.K., WU, P., WIDELITZ, R.B. and CHUONG, C.M. (2002) The morphogenesis of feathers. Nature. 420: 308-312.

YU, MK., YUE, ZC., WU, P., MAYER, JA., MEDINA, M., WIDELITZ, RB., JIANG, TX. and CHUONG, CM. (2004) The developmental biology of feather follicles. Int. J. Dev. Biol. (2004). 181-191.

ZUST, B (1971). Le developpement du plumage, dapres lanalyses des malformations cutanees produites par ladministration dhydrocortisone a lembryon de Poulet. Ann. Embrol. Morpho. 4: 155-174. 